\title{
Functional characterization of adrenocortical masses in nononcological patients using
} [68Ga]-pentixafor

Jie Ding ${ }^{1}$, Anli Tong ${ }^{2}$, Yushi Zhang ${ }^{3}$, Jin Wen³ ${ }^{3}$ Hui Zhang ${ }^{4}$, Marcus Hacker ${ }^{5}$, Li Huo1, Xiang $\mathrm{Li}^{5}$

${ }^{1}$ Department of Nuclear Medicine, Beijing Key Laboratory of Molecular Targeted Diagnosis and Therapy in Nuclear Medicine and State Key Laboratory of Complex Severe and Rare Diseases, Peking Union Medical College (PUMC) Hospital, Chinese Academy of Medical Science and PUMC, Beijing, China;

2 Department of Endocrinology and Key Laboratory of Endocrinology, Ministry of Health, PUMC Hospital, Chinese Academy of Medical Science and PUMC, Beijing, China;

${ }^{3}$ Department of Urological Surgery, PUMC Hospital, Chinese Academy of Medical Science and PUMC, Beijing, China;

${ }^{4}$ Department of pathology, PUMC Hospital, Chinese Academy of Medical Science and PUMC, Beijing, China;

${ }^{5}$ Division of Nuclear Medicine, Department of Biomedical Imaging and Image-guided Therapy, Medical University of Vienna, Vienna, Austria. 
* Correspondence to:

Prof. Li Huo, MD.

1\# Shuaifuyuan, Dongcheng District, Beijing, China, 100730

Email: huoli@pumch.cn

First Author:

Jie Ding, MD.

1\# Shuaifuyuan, Dongcheng District, Beijing, China, 100730

Email: 707462902@qq.com

Financial support: This work was sponsored in part by the National Natural Science Foundation of China (Grant No. 82071967), CAMS Initiative for Innovative Medicine (No. CAMS-2018-I2M-3-001), Tsinghua University-Peking Union Medical College Hospital Initiative Scientific Research Program (Grant No. 52300300519), Capital 's Funds for Health Improvement and Research (CFH-2018-2-4014). No other potential conflict of interest relevant to this article was reported.

Word count: 5501 words

Running title: ${ }^{68} \mathrm{Ga}$-pentixafor for adrenal lesions 


\section{ABSTRACT}

Purpose: We aimed to investigate the diagnostic and prognostic value of ${ }^{68} \mathrm{Ga}$-pentixafor positron emission tomography (PET)/computed tomography (CT) imaging in non-cancer patients with suspected adrenal masses.

Methods: Sixty-four patients who had benign adrenal masses on CT were retrospectively included in our study. All patients underwent ${ }^{68} \mathrm{Ga}$-pentixafor PET/CT scans, and 56 of these patients subsequently underwent adrenalectomy. The subtypes of 81 adrenal tumors including 14 nonfunctioning adrenal nodules, 4 cortisol-producing adenomas, 41 aldosterone-producing adenomas, 5 suspected unilateral adrenal hyperplasia, 15 idiopathic aldosterone hyperplasia and 2 pheochromocytomas, were determined by histology or follow-up evaluations. The functional lateralization diagnosis efficiency was calculated by visual analysis. Semiquantitative parameters of these lesions including maximum standardized uptake value (SUV $\max$ ), the ratio of lesional $S U V_{\max }$ to normal liver $S U V_{\text {mean }}(L L R)$, and the ratio of lesional $\mathrm{SUV}_{\max }$ to contralateral adrenal tissue $\mathrm{SUV}_{\text {mean }}(\mathrm{LCR})$ have also been calculated. Dynamic analysis has also been performed on fifteen patients. Besides, clinical outcomes were assessed and compared in patients who underwent adrenalectomy.

Results: The sensitivity and specificity of ${ }^{68} \mathrm{Ga}$-pentixafor PET for functional lateralization of patients with adrenocortical lesions were $97.8 \%$ (45/46) and $87.5 \%(14 / 16)$ respectively. The two pheochromocytoma lesions had lower pentixafor uptake compared to the normal adrenal glands. Functioning (active) adrenocortical adenomas showed an elevated SUV $\max$ of $16.3 \pm 7.9$ 
in comparison to $4.4 \pm 1.7$ in nonfunctioning (inactive) adenomas and $5.5 \pm 2.7$ in hyperplasia lesions $(P<0.0001)$. To identify active adrenocortical adenomas, a cutoff value of 7.1 for SUV $V_{\max }$ showed a sensitivity of $90.9 \%$ and a specificity of $85.3 \% \quad(A \cup C=0.96, P<0.0001)$; a cutoff value of 2.5 for LLR showed a sensitivity of $95.5 \%$ and a specificity of $88.2 \%$ (AUC=0.97, $P<0.0001)$; and a cutoff value of 2.4 for LCR showed a sensitivity of $88.6 \%$ and a specificity of 91.8\% (AUC=0.95, $P<0.0001$ ). The graphical $\mathrm{K} i$ of active adrenocortical adenomas was significantly higher than in-active adenomas. Uptake values for ${ }^{68} \mathrm{Ga}$-pentixafor were significantly higher in patients with preferable outcomes (cured/improved) (SUV $\max =15.5 \pm 8.0$, $\mathrm{LLR}=6.5 \pm 4.3, \mathrm{LCR}=6.2 \pm 5.0$ ) than in patients with nonpreferable outcomes (no improvement) $\left(\mathrm{SUV}_{\max }=4.2 \pm 0.5, \mathrm{LLR}=1.3 \pm 0.2, \mathrm{LCR}=1.5 \pm 0.6\right.$, all $\left.P<0.0001\right)$

Conclusion: ${ }^{68} \mathrm{Ga}$-pentixafor $\mathrm{PET} / \mathrm{CT}$ imaging exhibits great potential for noninvasive functional lateralization and characterization of patients with adrenocortical masses.

Keywords: adrenocortical masses; endocrine hypertension; ${ }^{68} \mathrm{Ga}$-pentixafor 


\section{INTRODUCTION}

The widespread use of conventional imaging modalities has increased the identification of adrenal masses. Adrenocortical adenomas, which are generally non-functioning adrenal adenomas (NFAs), account for $36 \%-94 \%$ of adrenal incidentalomas diagnosed in patients without malignant diseases (1). Functional adrenocortical adenomas are associated with increased morbidity and elevated mortality as compared with NFAs. Adrenalectomy is indicated in patients with suspected malignancies or functional adrenal tumors, whereas active surveillance is recommended for patients with NFAs (2).

Thereby, It is essential to determine the hormonal secretion of adrenal lesions (e.g., aldosterone-producing adenoma [APA] causing primary hyperaldosteronism [PA] patients or cortisol-producing adenoma [CPA] in Cushing's syndrome [CS] patients or pheochromocytomas [PCCs] versus NFAs), and lateralizing the disease to a single adrenal

gland (e.g., unilateral APA or unilateral adrenal hyperplasia[UAH] versus idiopathic aldosterone hyperplasia[IAH] in PA patients or unilateral versus bilateral functional adenoma), is essential for surgical management for adrenal benign lesions; bilateral IAH are treated with medication (2-4).

Identifying the functional distinctions between adrenal nodules remains challenging $(3,4)$. The functional diagnostic workup of adrenal masses, including screening, confirmatory test and subtype differentiation, are based on a combination of clinical symptoms, the presence of adrenal hormonal disorders, radiographic features, and the results of adrenal venous sampling 
(AVS). AVS is highly recommended for lateralization since the increased occurrence rate of NFA in older patients (>age 35) (4,5). However, the clinical manifestations of endocrine diseases are diverse, and a lack of uniformity in diagnostic protocols and assay methods for determining hormonal disorders in adrenal masses results in significant variability in measurements. Besides, the conventional imaging provides lesional morphology but not its functional status. If the diagnosis is based solely on adrenal CT, non-functional unilateral adrenal macroadenomas are indistinguishable from APAs, and small APAs may be misidentified as IAH by radiologists. (3). An effective and non-invasive workup would be helpful to obviate the need of AVS for the characterization of adrenal masses and their therapeutic management.

The potential utility of molecular imaging in the investigation of adrenal disorders has been recognized. The CXC chemokine receptor type 4 (CXCR4), which is a G protein-coupled receptor expressed on the surface of the cell membrane, contributes to the development and progression of malignancies. CXCR4 expression has been reported to be upregulated in APAs and CPAs; however, its expression is almost negligible in NFAs (6). Besides, CXCR4 is also hardly expressed by the tumor cells in paragangliomas (7). ${ }^{68} \mathrm{Ga}$-pentixafor, a CXCR4-specific PET tracer, may therefore be effective for the evaluation of the functional lateralization of adrenal lesion and identification of functional adrenocortical adenomas. In this pilot study, we aimed to develop ${ }^{68} \mathrm{Ga}$-pentixafor PET/CT as a noninvasive test for the recognition of 
functional adrenocortical lesions and to help guide the management of non-oncological patients with suspicious adrenal tumors. 


\section{METHODS AND MATERIALS}

\section{Patients and clinical diagnosis}

In this retrospective study, we included 66 non-oncological patients with adrenal nodules who underwent ${ }^{68} \mathrm{Ga}$-pentixafor PET/CT examinations between August 1, 2018 and August 30, 2019. The patients with a history of malignancy were excluded. Before PET/CT examination, adrenal CT was performed in the patients. A series of continuous patients of adrenal disease with the features of benign adrenal masses (homogeneous lesions with smooth margins) identified on adrenal CT were included in our study. The patients were referred to us by a certified specialist in clinical endocrinology or in urology, because the adrenal masses were incidentally $(n=55)$ or specific (e.g. patients with endocrine symptoms, $\mathrm{n}=11$ ) discovered during an abdominal imaging procedure.

Two patients with an adrenal malignant lesion or non-adrenal lesion were excluded. Thus, 64 patients were analyzed in this study finally, with diagnoses based on clinical variables, laboratory assessments, adrenal CT imaging, the results of AVS examination (4 patients) histopathologic examinations, and follow-up evaluations (median $22.5 \pm 4.1$ months). The diagnosis criteria are listed in the supplementary materials $(8,9)$.

Written informed consent to undergo ${ }^{68} \mathrm{Ga}$-pentixafor PET imaging was obtained from all patients, and the consent form and study were approved by the Ethical Committee of PUMCH (IRB protocol \#ZS-1435). 


\section{Static and dynamic PET imaging}

The preparation of ${ }^{68} \mathrm{Ga}$-pentixafor was conducted as has previously been described (10), with a radiochemical purity of at least $95 \%$. All images were acquired using a dedicated PET/CT scanner (PoleStar m660; SinoUnion Healthcare Inc., Beijing, China) at the Peking Union Medical College Hospital. Fifteen patients with 16 adrenal lesions underwent 30-min dynamic imaging (including 11 APA lesions and 5 NFA lesions) starting immediately after intravenous injection of a ${ }^{68} \mathrm{Ga}$-pentixafor $(128.0 \pm 77.0 \mathrm{MBq})$ bolus. The reconstruction methods are attached in the Supplementary Materials. In the other 49 patients, static imaging of the upper abdomen and adrenal region was performed over 5 min using a single bed, with an uptake time of $25-30 \mathrm{~min}$ after injection of $87.7 \pm 64.8 \mathrm{MBq}$ of ${ }^{68} \mathrm{Ga}$-pentixafor.

\section{Imaging analysis}

On visual analysis of the static images, ${ }^{68} \mathrm{Ga}$-pentixafor-avid adrenal nodules were defined as those showing a higher uptake of ${ }^{68} \mathrm{Ga}$-pentixafor on PET imaging than ipsilateral/contralateral normal adrenal glands. The scan was considered negative if it showed an equal or lesser uptake of ${ }^{68} \mathrm{Ga}$-pentixafor compared with the normal adrenal glands. The presence of ${ }^{68} \mathrm{Ga}$-pentixafor-avid adrenal nodules indicated the adrenal lateralization.

For semiquantitative analysis of ${ }^{68} \mathrm{Ga}$-pentixafor PET/CT data, spherical VOls were assigned to the center of adrenal lesions using CT images and the normal adrenal gland. Another VOI was placed in the liver adjacent to the right adrenal gland (2-cm diameter sphere). 
The maximum standard uptake value of lesions (SUV $V_{\max }$ ), the ratio of the lesional $S U V_{\max }$ to the normal liver SUV mean (LLR), and the ratio of the lesional SUV $\mathrm{V}_{\max }$ to the contralateral adrenal tissue SUVmean $(\mathrm{LCR})$ were calculated.

All scans were interpreted by nuclear medicine physicians ( $H L$ and $D J)$ experienced in ${ }^{68} \mathrm{Ga}$-pentixafor PET interpretation; they were blinded to the clinical information. A joint reevaluation was performed in case of incongruent scan interpretation. The preliminary results that were categorized as lateralization (eg. right, left, bilateral positive, or negative), which were used to assist the clinician in the for diagnosis and management of patients. Upon completion of the follow-up, all scans were retrospectively reviewed. The results that represented as clinical diagnosis with lateralization (eg. APA_left, CPA_right) were used for final retrospective analysis (Supplement table1).

\section{Patients therapy management and outcomes}

The management of patients was co-determined by endocrinologists and urologists based on clinical and imaging presentations. Fifty-six patients underwent adrenalectomy with subsequent pathologic analysis. Of these, 47 patients (83.9\%) underwent adrenalectomy for suspected adrenal endocrine disease (43 for suspected APA, 3 for suspected CPA and 1 for suspected PCC). Nine suspected NFA patients (16.1\%) underwent adrenalectomy because of tumor growth. Three primary suspected APA patients did not undergo surgery because of poor physical fitness. Five patients received medical treatment for primary suspected IHA. 
The outcomes assessment criteria of postoperative patients with adrenocortical lesions were listed on the supplement materials (11). The outcomes of PA and CS patients were classified into three groups (cured, improved and nonimproved) while the NFA patients were classified into two groups (nonimproved and no changed). The median follow-up time from surgery was $22.2 \pm 3.9$ months. A flow diagram of patient enrollment, treatment, and followup evaluations is presented in Figure 1.

\section{Histology and immunohistochemistry of CXCR4}

Hematoxylin and eosin (HE) staining and immunohistochemical analyses were performed using paraffin-embedded specimens by two experienced pathologists. HE staining was performed according to routine clinical protocols. Immunohistochemical analysis of CXCR4 was performed in 36 patients using paraffin-embedded specimens. The dilution of the CXCR4 antibody (ab124824; Abcam) was 1:100. For each tumor, a value designated as the $\mathrm{H}$ score was then obtained by multiplying the intensity score based on the percentage score.

Subsequently, it was classified into three groups (0-4, 4-8 and 8-12). Then the difference of SUV $V_{\max }$ of ${ }^{68} \mathrm{Ga}$ pentixafor between the three groups of $\mathrm{H}$ score were calculated and analyzed. The analysis of immunohistochemistry of CXCR4 is attached in the Supplementary Materials. 


\section{Statistical analysis}

All data were processed using SPSS 22.0 and GraphPad Prism 8 statistical software. The sensitivity and specificity of ${ }^{68} \mathrm{Ga}$-pentixafor PET/CT visual analysis for adrenal functional lateralization were calculated. The semi-quantitative variables (SUV $\max$, LLR, and LCR) were compared using ANOVA in categorized adrenocortical lesions (adenoma-active, adenomainactive/hyperplastic). The correlation between the $\mathrm{SUV}_{\max }$ and the $\mathrm{H}$ score was calculated with Pearson correlation. The sensitivity and specificity of ${ }^{68} \mathrm{Ga}$-pentixafor PET/CT semiquantitative analysis results for discriminating the adenoma-active group from the nonadenoma-active group were calculated. Receiver-operating characteristic (ROC) curve analysis was conducted to calculate the thresholds of semi-quantitative variables for the identification of active adrenal adenomas. Analysis items with a $P$-value of $<0.05$ were considered statistically significant.

\section{RESULTS}

\section{Baseline characteristics and clinical management of patients}

Sixty-four patients (33 women and 31 men) aged $47 \pm 10$ years were included in our study. The baseline clinical characteristics of the patients are listed in Table 1. The detailed information of all patients was listed on the Supplemental Table 1. The final diagnoses of these 64 patients included 51 PA patients (40 with APA, 3 with sUAH [suspected $U A H$, the detail is attached in the Supplement (11)] and 8 with IAH), 3 CPAs patients, 8 NFA patients, and two 
PCC patients (Table 2). 98\% (50/51) PA patients suffered from hypertension and $86.3 \%(44 / 51)$ had hypokalemia. 3 CPAs patients presented typical cushingoid symptoms including weight gain, facial plethora, menstrual disorder, increased waist circumference and proximal muscle weakness. 75\% (6/8) NFA patients without discernible symptoms and 25\% (2/8) NFA patients had essential hypertension. One PCC patient presented with paroxysmal hypertension and another patient was asymptomatic with a silent PCC lesion. With the laboratory findings, PA patients showed increased plasma aldosterone-renin ratios (ARR) than the other groups $(P<$ 0.05). Patients with CPAs had increased serum corticosteroid and 24h-urinary free cortisol (UFC) levels. 38(74.5\%) PA patients underwent the captopril challenge test, and $35(92.1 \%)$ cases were positive (Supplemental Table 1).

\section{Lesional characteristics and clinical imaging manifestations}

There were 81 adrenal lesions $(1.8 \pm 0.8 \mathrm{~cm}$, range: $0.6-4.0 \mathrm{~cm})$ in these 64 patients, including APAs ( $n=41)$, sUAH $(n=5), \operatorname{IAH}(n=15)$, CPAs $(n=4)$, NFAs $(n=14)$ and PCC $(n=2)$. All lesions presented with typical benign manifestations on CT imaging, with homogeneous and smooth margins (except PCC lesions presenting multiple cystic changes within the tumor). The imaging features of these lesions are shown in Table 3. 


\section{Visual assessment by ${ }^{68}$ Ga-pentixafor PET imaging and outcome}

In the visual per-patient analysis, $97.5 \%(39 / 40)$ of APA patients, $100 \%(3 / 3)$ of sUAH patients, and $100 \%$ (3/3) of CPA patients were positive on ${ }^{68} \mathrm{Ga}$-pentixafor PET/CT, while $87.5 \%$ (7/8) of IAH patients, $87.5 \%$ (7/8) of NFA patients and 100\% (2/2) PCC patients were negative on ${ }^{68} \mathrm{Ga}$-pentixafor PET. These adrenocortical lesions were classified into two groups ([APA, $\mathrm{UAH}$ and CPA] and [IAH and NFA]). The sensitivity and specificity of ${ }^{68} \mathrm{Ga}$-pentixafor PET for functional lateralization (identification for APA, UAH, and CPA) of patients were $97.8 \%(45 / 46)$ and $87.5 \%(14 / 16)$ respectively. The representative ${ }^{68} \mathrm{Ga}$-pentixafor PET/CT imaging in patients with unilateral adrenal cortical nodules is shown in Figure 2.

In 51 PA patients, a true positive for ${ }^{68}$ Ga-pentixafor adrenal uptake occurred in 42 patients (39 APA and 3 sUAH) $(97.7 \%, 42 / 43)$, and true negative uptake occurred in 7 IAH patients $(87.5 \%, 7 / 8)$. A false-negative scan was found in one APA patient, and a false positive scan occurred in one IAH patient. Ten PA patients presented with bilateral adrenal lesions, and ${ }^{68} \mathrm{Ga}$-pentixafor successfully identified the functional lateralization in nine patients. A total of 37 APA patients underwent adrenalectomy (36 unilateral and 1 bilateral), resulting in 24 patients being cured and 13 patients showing improvement. Three sUAH patients underwent unilateral adrenalectomy and were cured, while three IAH patients underwent adrenalectomy because of a clinical misdiagnosis of APA; two of these patients showed non-improvement while one patient showed improvement. 
All three CS patients showed ${ }^{68} \mathrm{Ga}$-pentixafor-avid adrenal nodules (two unilateral and one bilateral); all these patients were cured after adrenalectomy (two unilateral and one bilateral).

$7 / 8(87.5 \%)$ NFA patients had a true negative PET scan; one NFA patient had a falsepositive PET scan. Eight NFA patients underwent a unilateral adrenalectomy. Two of these patients remained non-improved, with six of these showing no change. The PET scans of the two PCC patients were both negative.

\section{Semiquantitative analysis of PET/CT}

The SUV $\max$, LLR, and LCR of the adrenocortical tumors are listed in Table 3. The highest radiotracer uptake was identified in patients with APA (SUV $\max 36.4$ ). Besides, a significant correlation between uptake on ${ }^{68} \mathrm{Ga}$-pentixafor and histological CXCR4 expression was noted. The H score of CXCR4 was significantly correlated with the SUV $\max$ of ${ }^{68} \mathrm{Ga}$-pentixafor $(r=0.66$, $P<0.0001)$. The $\mathrm{SUV}_{\max }$ of $8-12$ group of $\mathrm{H}$ score was significantly higher than the two other groups (Figure 3). The uptake was significantly higher in the adenoma-active group than in either the adenoma-inactive group or the hyperplasia (sUAH and IAH) group (Figure 3). The thresholds of SUV $V_{\max }$, LLR, and LCR and the corresponding sensitivities, specificities and the area under the curve (AUC) of the ROC curves to distinguish the adenoma-inactive group from the non-active-adenoma lesion group are shown in Figure 3. 


\section{The analysis of dynamic PET imaging}

The graphical Ki was significantly higher for adrenocortical active adenomas $(0.28 \pm 0.8$, $\mathrm{n}=11)$ than for inactive adenomas $(0.10 \pm 0.06, \mathrm{n}=5, P<0.05)$, normal adrenal glands $(0.08 \pm 0.04$, $\mathrm{n}=16, P<0.05)$, or the liver $(0.04 \pm 0.03 ; \mathrm{n}=16, P<0.05)$. Figure 4 shows the TACs for normal adrenal tissue, liver, plasma, adrenocortical active adenomas, and inactive adenomas on ${ }^{68} \mathrm{Ga}$-pentixafor dynamic $\mathrm{PET} / \mathrm{CT}$ imaging in 15 patients. In this figure, the spots represent the mean value of SUVmean at each time point, with the radioactivity distribution remaining stable after early phase (5-10 min after injection).

\section{${ }^{68}$ Ga-pentixafor uptake and outcomes}

In the total of 48 patients with adrenocortical adenomas/hyperplasia who underwent adrenalectomy (except 6 asymptomatic NFA patients), the uptake values of resected adrenal lesions for ${ }^{68} \mathrm{Ga}$-pentixafor were significantly higher in patients with preferable outcomes (cured and improved) than with nonpreferable outcomes (non-improved) $(P<0.001$, Figure 5). The SUV $\max$, LLR, and LCR of ${ }^{68} \mathrm{Ga}$-pentixafor in patients with preferable and nonpreferable outcomes were $15.5 \pm 8.0$ versus $4.2 \pm 0.5,6.5 \pm 4.3$ versus $1.3 \pm 0.2$, and $6.2 \pm 5.0$ versus $1.5 \pm 0.6$ $(P<0.001)$, respectively. Additionally, uptake values in the cured group were higher than in the improved group but without statistical significance (Figure 5).

\section{Comparison between AVS and ${ }^{68}$ Ga-pentixafor PET/CT}


Four patients underwent both AVS and ${ }^{68} \mathrm{Ga}$-pentixafor PET/CT imaging (Table 4).

Two patients with APA showed true-positive findings on both examinations, and one patient presented with a false-negative APA lesion on AVS versus a true-positive lesion on PET/CT scanning. Additionally, one patient with IAH presented with a false-positive result on AVS versus a true-negative result on PET/CT scanning, which was all determined by outcome evaluations.

\section{DISCUSSION}

Functional lateralization of the patients with adrenocortical lesions, along with distinguishing functioning lesions from nonfunctioning lesions in non-oncological patients is crucial for the therapeutic management of these patients. Conventional lateralization and the functional assessment of adrenal masses are usually performed using adrenal CT imaging or AVS. In this pilot study, we evaluated the performance of ${ }^{68} \mathrm{Ga}$-pentixafor PET/CT imaging for the functional lateralization of adrenal lesions and its effectiveness in identifying functional adrenal adenomas to help guide management decisions. The initial finding for APA lesions detection in patients with PA was reported pioneeringly (10). In the present study, we furtherly included 28 patients (including 22 PA, 1 NFA, 3 CS and 2 PCC patients) with relatively heterogeneous adrenal tumour types, which was an extension from the previous reports and provided complementary evidence for potential implementation of adrenal benign mass screening by ${ }^{68} \mathrm{Ga}-$ pentixafor PET/CT. 


\section{Diagnostic efficacy and clinical significance of ${ }^{68}$ Ga-pentixafor PET/CT.}

Hormonal assessments are crucial when investigating adrenal masses; however, several important considerations must be accounted for during these evaluations, including daily hormonal rhythms, sex/age dependency, limitations of assays, substantial variability in cutoff values, and drug interactions (3). In addition, it is important to remember that anatomical imaging approaches (e.g., CT imaging and MRI) are limited in their ability to functionally and molecularly characterize adrenal masses due to limitations in their resolutions and specificities, as well as the presence of substantial interobserver variation (12). In our study, ${ }^{68} \mathrm{Ga}$-pentixafor PET was effective for the lateralization of adrenal disease. An APA patient with a single $0.6 \mathrm{~cm}$ lesion had a false negative PET scan in our study, which might indicate the limitation of this technique for small lesions with reduced spatial resolution. Semiquantitative variables (SUV and SUV ratios) yielded excellent sensitivities and specificities for discriminating active adrenocortical adenomas. The time-activity curves (TAC) of the lesions showed a steady early tracer retention after tracer injection in active adenomas. ${ }^{68} \mathrm{Ga}$-pentixafor PET/CT was negative for PCC lesions, which indicates the potential ability of ${ }^{68} \mathrm{Ga}$-pentixafor to distinguish cortical from non-cortical adrenal masses. Moreover, this study also demonstrated the high sensitivity of $\left[{ }^{68} \mathrm{Ga}\right.$-pentixafor in the localization of CPAs. However, the number of cases is limited, the further prospective investigations are warranted to determine the values and pitfalls of ${ }^{68} \mathrm{Ga}$-pentixafor in diagnosis and follow-up of patients with CPA. 
In this study, patients who had a false negative or false CT diagnoses could be potentially be correctly diagnosed based on the ${ }^{68} \mathrm{Ga}$-pentixafor PET (see supplemental results). However, further research is warranted regarding the utility of ${ }^{68} \mathrm{Ga}$-pentixafor PET compared with $\mathrm{CT}$ for establishing a diagnosis and treatment plan in patients with adrenal disease. ${ }^{68} \mathrm{Ga}$ pentixafor demonstrated a promising prognostic predictive value after therapy, nononcological patients were more likely to have preferable outcomes after adrenalectomy for

${ }^{68}$ Ga-pentixafor-avid adrenal lesions (see supplemental figure 1).

AVS is the gold standard for assessing the laterality of PA, it's technically challenging with only a $50 \%-80 \%$ success rate for adrenal vein cannulation and risk of complications (13-16). In our study, distinct results were identified between ${ }^{68}$ Ga-pentixafor PET and AVS examinations. The consistency and difference between the two examinations are worthy of being determined in further studies.

\section{Potential underlying mechanisms for adrenal uptake of ${ }^{68}$ Ga-pentixafor}

Published studies demonstrated that $G$ protein-coupled receptors can increase the transcriptional and promoter activity of the CYP11B2 (aldosterone synthase) gene, suggesting they may cause adenomas to increase their capacity to produce aldosterone $(17,18)$. Previous studies have also shown that steroid production in some CPAs is regulated by aberrant expression of G protein-coupled receptors (19-21). However, Heinze et al. have demonstrated 
that only $26 \%$ of CPAs showed prominent CXCR4 expression (6). Further investigation is warranted to correlate ${ }^{68} \mathrm{Ga}$-pentixafor uptake with CXCR4 expression.

\section{Comparison to other radiopharmaceuticals}

NP-59 has been used to investigate the secretory status of adrenal adenomas and to aid in lesion lateralization; however, this technique has significant shortcomings, including increased radiation exposure to the adrenal glands, longer acquisition procedures, low sensitivities, and poor spatial resolution (22). ${ }^{123} /{ }^{11} \mathrm{C}$-metomidate, an inhibitor of $11 \beta$ hydroxylase, was introduced as a novel PET tracer for adrenocortical imaging; however, it could not distinguish between active and inactive adenomas (23). Moreover, the short half-life of ${ }^{11} \mathrm{C}$ limits its clinical use. In contrast, the acquisition time window for ${ }^{68} \mathrm{Ga}$-pentixafor PET/CT imaging is long and can be performed as early as $5-10$ min after administration. All in all, ${ }^{68} \mathrm{Ga}-$ pentixafor PET/CT imaging may be a noninvasive, feasible, and effective method for preoperative diagnoses of adrenal incidentalomas, particularly for lateralization of patients presenting bilateral lesions.

\section{Limitations}

This study had several limitations. Firstly, prospective randomization was not feasible at this stage, which potentially led to biases in selection and findings. Secondly, the statistical significance was not sufficient because of the small sample size. Thereby, a prospective, 
randomized, controlled trial is highly warranted to compare ${ }^{68} \mathrm{Ga}$-pentixafor $\mathrm{PET} / \mathrm{CT}$ with other approaches for obtaining preoperative diagnoses in patients with PA or suspected adrenal masses. Thirdly, the majority of positive findings in our study are APAs vs. small number of CPA cases, and there is a request for further evidence for the capability of ${ }^{68} \mathrm{Ga}$-pentixafor $\mathrm{PET} / \mathrm{CT}$ in distinct types of functional adrenal masses.

\section{CONCLUSION}

In summary, ${ }^{68} \mathrm{Ga}$-pentixafor exhibited excellent sensitivity and specificity for the functional lateralization of adrenal disease. The ${ }^{68} \mathrm{Ga}$-pentixafor PET/CT shows a great potential for use in the therapeutic management of patients with adrenal masses.

DISCLOSURE: This work was sponsored in part by the National Natural Science Foundation of China (Grant No. 82071967), CAMS Initiative for Innovative Medicine (No. CAMS-2018I2M-3-001), Tsinghua University-Peking Union Medical College Hospital Initiative Scientific Research Program (Grant No. 52300300519), Capital 's Funds for Health Improvement and Research (CFH-2018-2-4014). No other potential conflict of interest relevant to this article was reported. 


\section{KEY POINTS:}

Question: Does ${ }^{68} \mathrm{Ga}$-pentixafor have diagnostic and prognostic value for evaluating patients with primary adrenal cortical tumors?

Pertinent findings: ${ }^{88} \mathrm{Ga}$-pentixafor uptake was significantly higher in the adenoma-active group than in either the adenoma-inactive group or the hyperplasia group. Patients with ${ }^{68} \mathrm{Ga}-$ pentixafor-avid lesions had more preferable outcomes after adrenalectomy.

Implications for patient care: ${ }^{68} \mathrm{Ga}$-pentixafor showed excellent performance in the management of patients with typical benign adrenal lesions on CT imaging. This technique may also be a highly promising method for predicting patient prognosis after adrenalectomy. 


\section{REFERENCES}

1. Mantero F, Terzolo M, Arnaldi G, et al. A survey on adrenal incidentaloma in Italy. Study Group on Adrenal Tumors of the Italian Society of Endocrinology. J Clin Endocrinol Metab. 2000;85:637-644.

2. Bourdeau I, El Ghorayeb N, Gagnon N, et al. MANAGEMENT OF ENDOCRINE DISEASE: Differential diagnosis, investigation and therapy of bilateral adrenal incidentalomas. Eur J Endocrinol. 2018;179:R57-R67.

3. Funder JW, Carey RM, Mantero F, et al. The management of primary aldosteronism: case detection, diagnosis, and treatment: an Endocrine Society Clinical Practice Guideline. J Clin Endocrinol Metab. 2016;101:1889-1916.

4. Fassnacht $\mathrm{M}$, Arlt $\mathrm{W}$, Bancos I, et al. Management of adrenal incidentalomas: European Society of Endocrinology Clinical Practice Guideline in collaboration with the European Network for the Study of Adrenal Tumors. Eur J Endocrinol. 2016;175:G1G34.

5. Garrett RW, Nepute JC, El Hayek M, Albert SG. Adrenal incidentalomas: clinical controversies and modified recommendations. AJR Am J Roentgenol. 2016;206:1170_ 1178.

6. Heinze B, Fuss CT, Mulatero P, et al. Targeting CXCR4 (CXC Chemokine Receptor Type 4) for molecular imaging of aldosterone-producing adenoma. Hypertension. 2018;71:317-325. 
7. Kaemmerer D, Sänger J, Arsenic R, et al. Evaluation of somatostatin, CXCR4 chemokine and endothelin A receptor expression in a large set of paragangliomas. Oncotarget. 2017;8:89958-89969.

8. Williams TA, Lenders JWM, Mulatero $P$, et al. Outcomes after adrenalectomy for unilateral primary aldosteronism: an international consensus on outcome measures and analysis of remission rates in an international cohort. Lancet Diabetes Endocrinol. 2017;5:689-699.

9. Lacobone M, Citton M, Viel G, et al. Unilateral adrenal hyperplasia: a novel cause of surgically correctable primary hyperaldosteronism. Surgery. 2012;152:1248-1255.

10. Ding J, Zhang Y, Wen J, et al. Imaging CXCR4 expression in patients with suspected primary hyperaldosteronism. Eur J Nucl Med Mol Imag. 2020;47:2656-2665.

11. Webb SM, Badia X, Barahona MJ, et al. Evaluation of health-related quality of life in patients with Cushing's syndrome with a new questionnaire. Eur $J$ Endocrinol. 2008;158:623-630.

12. Kempers MJE, Lenders JWM, van Outheusden L, et al. Systematic review: diagnostic procedures to differentiate unilateral from bilateral adrenal abnormality in primary aldosteronism. Ann Intern Med. 2009;151:329-337.

13. Mulatero P, Bertello C, Sukor N, et al. Impact of different diagnostic criteria during adrenal vein sampling on reproducibility of subtype diagnosis in patients with primary aldosteronism. Hypertension. 2010;55:667-673. 
14. Kline GA, So B, Dias VC, Harvey A, Pasieka JL. Catheterization during adrenal vein sampling for primary aldosteronism: failure to use (1-24) ACTH may increase apparent failure rate. J Clin Hypertens (Greenwich). 2013;15:480-484.

15. Seccia TM, Miotto D, De Toni R, et al. Adrenocorticotropic hormone stimulation during adrenal vein sampling for identifying surgically curable subtypes of primary aldosteronism: comparison of 3 different protocols. Hypertension. 2009;53:761-766.

16. Lethielleux G, Amar L, Raynaud A, Plouin PF, Steichen O. Influence of diagnostic criteria on the interpretation of adrenal vein sampling. Hypertension. 2015;65:849-854.

17. Saner-Amigh K, Mayhew BA, Mantero F, et al. Elevated expression of luteinizing hormone receptor in aldosterone-producing adenomas. J Clin Endocrinol Metab. 2006;91:1136-1142.

18. Itcho K, Oki K, Kobuke K, et al. Aberrant $\mathrm{G}$ protein-receptor expression is associated with DNA methylation in aldosterone-producing adenoma. Mol Cell Endocrinol. 2018;461:100-104.

19. Dall'Asta C, Ballarè E, Mantovani G, et al. Assessing the presence of abnormal regulation of cortisol secretion by membrane hormone receptors: in vivo and in vitro studies in patients with functioning and non-functioning adrenal adenoma. Horm Metab Res. 2004;36:578-583.

20. Bugalho MJ, Li X, Rao CV, Soares J, Sobrinho LG. Presence of a Gs alpha mutation in an adrenal tumor expressing LH/hCG receptors and clinically associated with 
Cushing's syndrome. Gynecol Endocrinol. 2000;14:50-54.

21. El Ghorayeb N, Bourdeau I, Lacroix A. Multiple aberrant hormone receptors in Cushing's syndrome. Eur J Endocrinol. 2015;173:M45-60.

22. Yen RF, Wu VC, Liu KL, et al. 131I-6beta-iodomethyl-19-norcholesterol SPECT/CT for primary aldosteronism patients with inconclusive adrenal venous sampling and CT results. J Nucl Med. 2009;50:1631-1637.

23. Minn H, Salonen A, Friberg J, et al. Imaging of adrenal incidentalomas with PET using (11)C-metomidate and (18)F-FDG. J Nucl Med. 2004;45:972-979. 


\section{FIGURES}

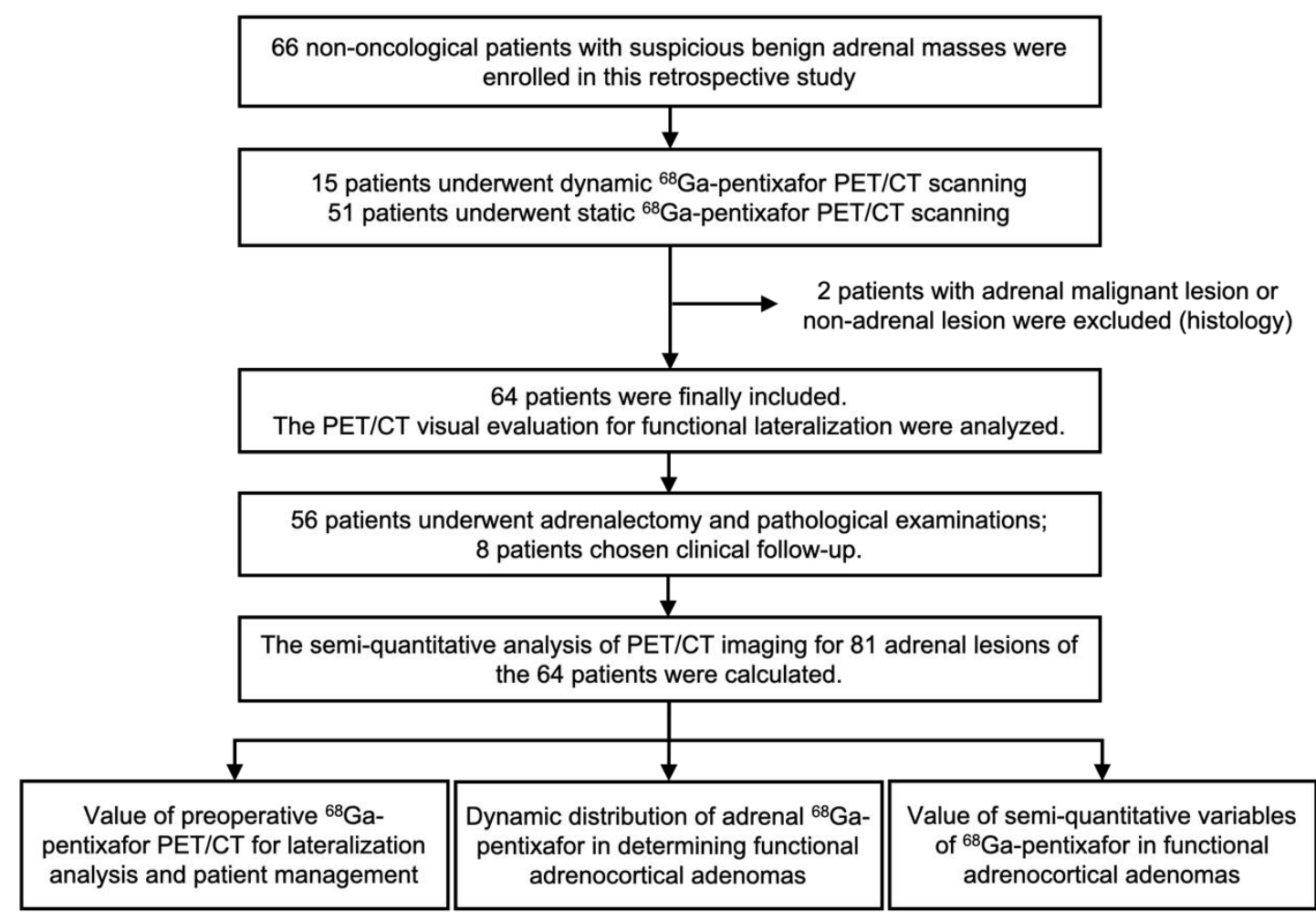

FIGURE 1. Flow diagram for enrollment, diagnosis, treatment, and follow-up examinations of patients. 


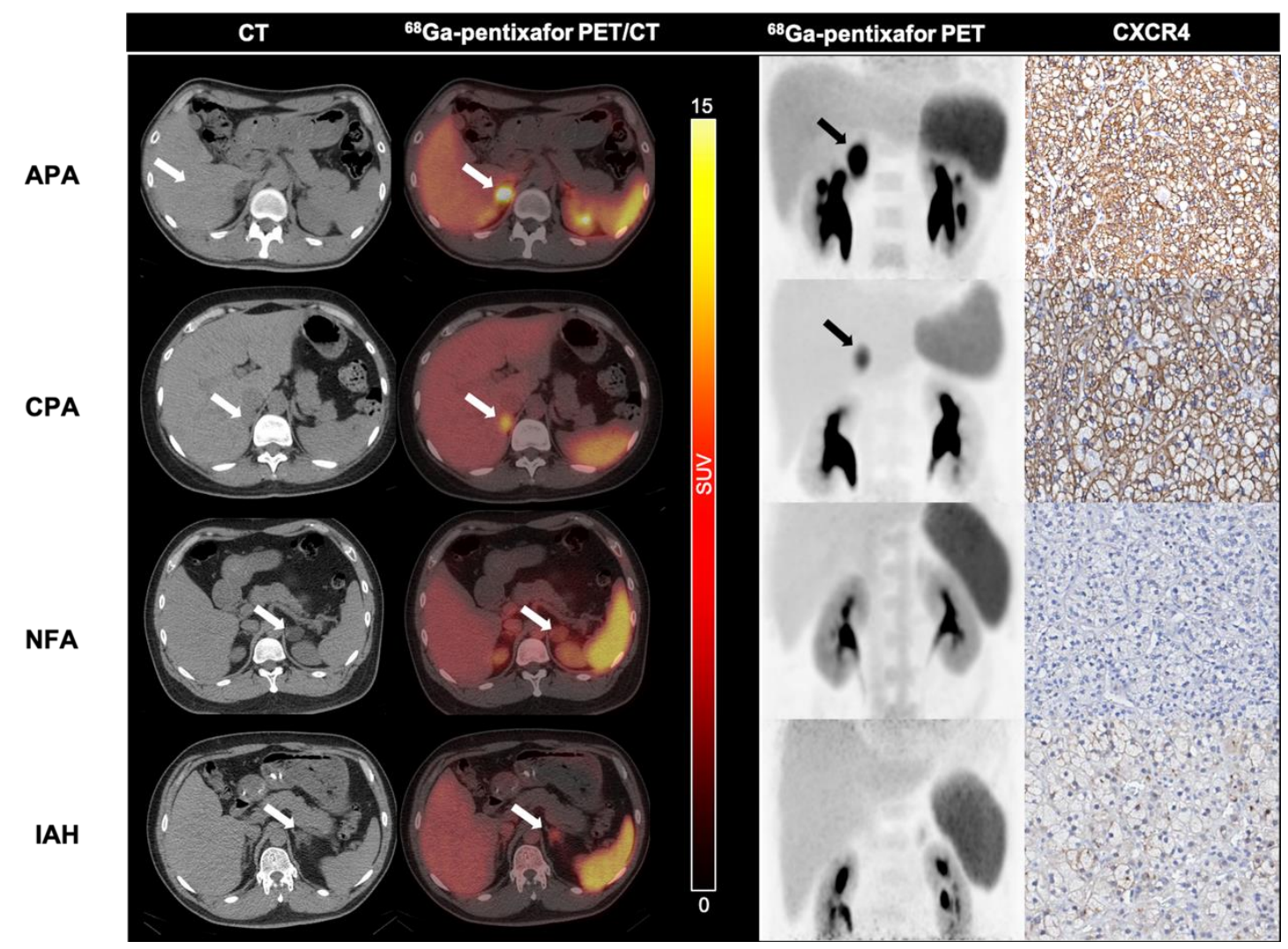

FIGURE 2. The performance of ${ }^{68} \mathrm{Ga}$-pentixafor PET/CT imaging in patients with adrenal cortical nodules. The first line of images displays a right adrenal aldosterone-producing adenoma (APA) $(2.9 \mathrm{~cm}$ in long diameter on CT imaging, white arrow) with positive findings on PET/CT and PET scanning (maximum standard uptake value (SUV $\max$ ) of 29.0, white/black arrows) and strong expression of CXCR4. The patient was a 34-year-old man with a 5-year history of hypertension and a 0.5-year history of hypokalemia (serum potassium was 2.9 $\mathrm{mmol} / \mathrm{L}$ ). The second line of images shows a pentixafor-avid cortisol-producing adenoma (CPA) in the left adrenal gland (SUV $\max$ of $14.8,1.9 \mathrm{~cm}$ in diameter on CT, white/black arrows) in a 36-year-old woman with Cushing syndrome. Strong expression of CXCR4 was observed on immunochemical staining. The third line of images shows a non-pentixafor-avid nonfunctioning adenoma (NFA) in the left adrenal gland ( $S U V_{\max }$ of $3.8,2.9 \mathrm{~cm}$ in long diameter on CT imaging, white arrows) in a 36-year-old man. This adenoma had no increases in CXCR4 expression. The last line of images shows a negative idiopathic adrenal hyperplasia (IAH) lesion ( $1.5 \mathrm{~cm}$ in long diameter on CT imaging, white arrow) in a 46-year-old man on ${ }^{68} \mathrm{Ga}$ pentixafor PET/CT and PET imaging (SUV $\max$ of 4.3, white arrow). No increased expression of CXCR4 was observed by immunochemical staining. 

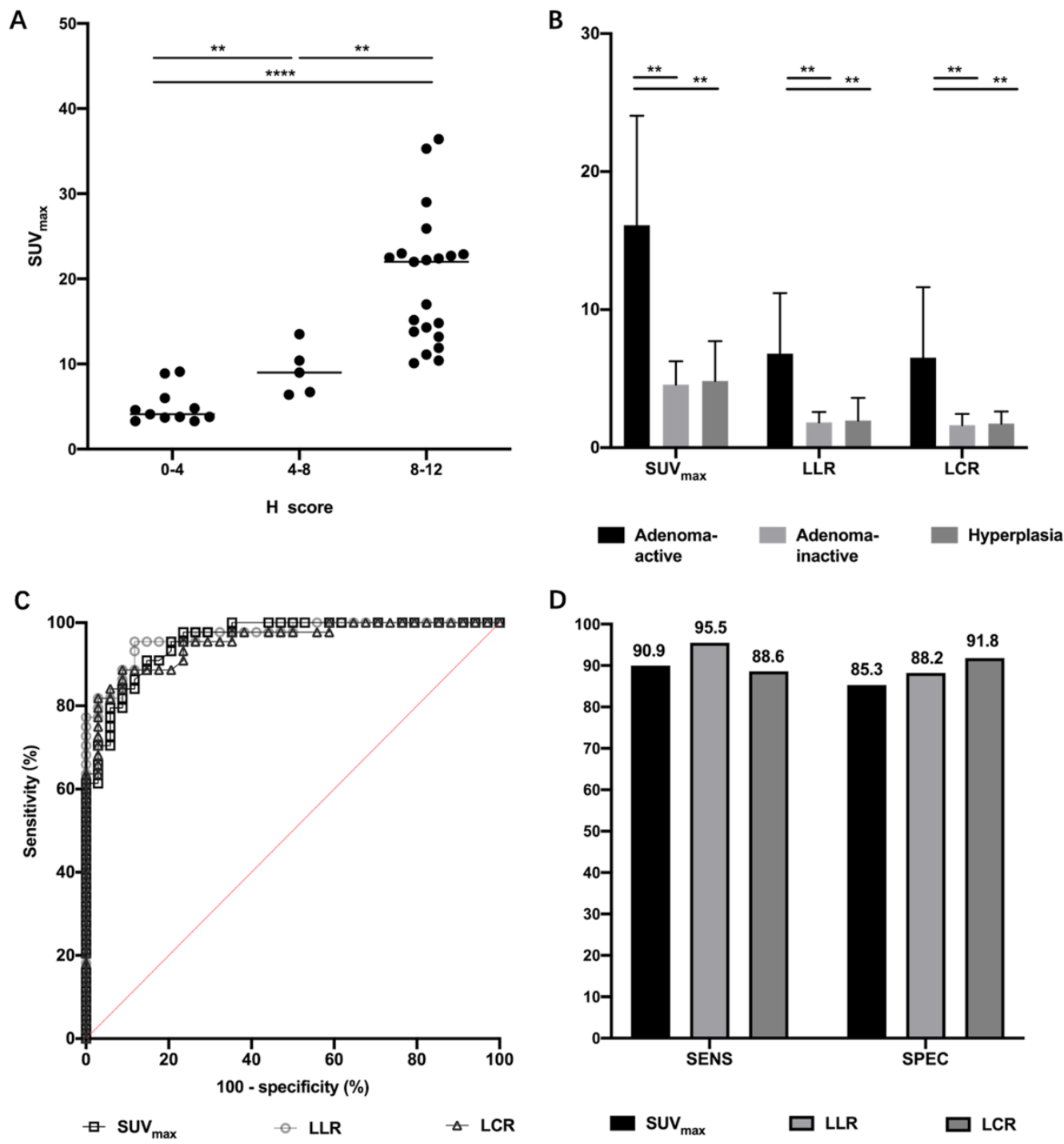

FIGURE 3. A. ${ }^{68} \mathrm{Ga}$-pentixafor maximum standard uptake value ( $\mathrm{SUV}_{\max }$ ) of three groups of $\mathrm{H}$ score $(0-4,4-8,8-12)$ were $5.0 \pm 2.1$ vs. $9.2 \pm 2.9$ vs. $19.8 \pm 7.7$ respectively. ${ }^{* *} P<0.001$

B. ${ }^{68} \mathrm{Ga}$-pentixafor $S U V_{\max }$, ratio of lesional $S U V_{\max }$ to normal liver SUV $V_{\text {mean }}(\mathrm{LLR})$, and ratio of lesional SUV $V_{\max }$ to contralateral adrenal tissue SUV $\mathrm{V}_{\text {mean }}$ (LCR) for adenoma-active, adenomainactive, and hyperplastic lesions (SUV $\max =16.3 \pm 7.9$ vs. $4.4 \pm 1.7$ vs. $5.5 \pm 2.7$; LLR $=6.8 \pm 4.3$ vs. $1.7 \pm 0.7$ vs. $1.7 \pm 0.8$; $L C R=6.5 \pm 5.1$ vs. $1.7 \pm 0.8$ vs. $1.8 \pm 0.6$, respectively). The $S U V_{\max }$ LLR, and LCR were significantly higher for adenoma-active lesions than adenoma-inactive or hyperplastic lesions. C. ROC analysis for determining optimal cutoff values for SUV $\mathrm{max}_{\operatorname{ma}}$ LLR, and LCR for differentiating active adenomas from non-active-adenoma lesions. The optimal thresholds for SUV $\max$, LLR, and LCR were 7.1, 2.5, and 2.4 respectively, with AUCs of ROC curves of $0.96,0.97$, and 0.95 , respectively, all $P<0.0001$. Sensitivities and specificities of 
SUV $\max$, LLR, and LCR for identifying active adenomas. The sensitivities of SUV max $_{\text {, LLR, and }}$ LCR were $95.5 \%, 95.5 \%$, and $84.1 \%$ respectively, with specificities of $82.7 \%, 85.7 \%$, and $91.4 \%$, respectively. 
A

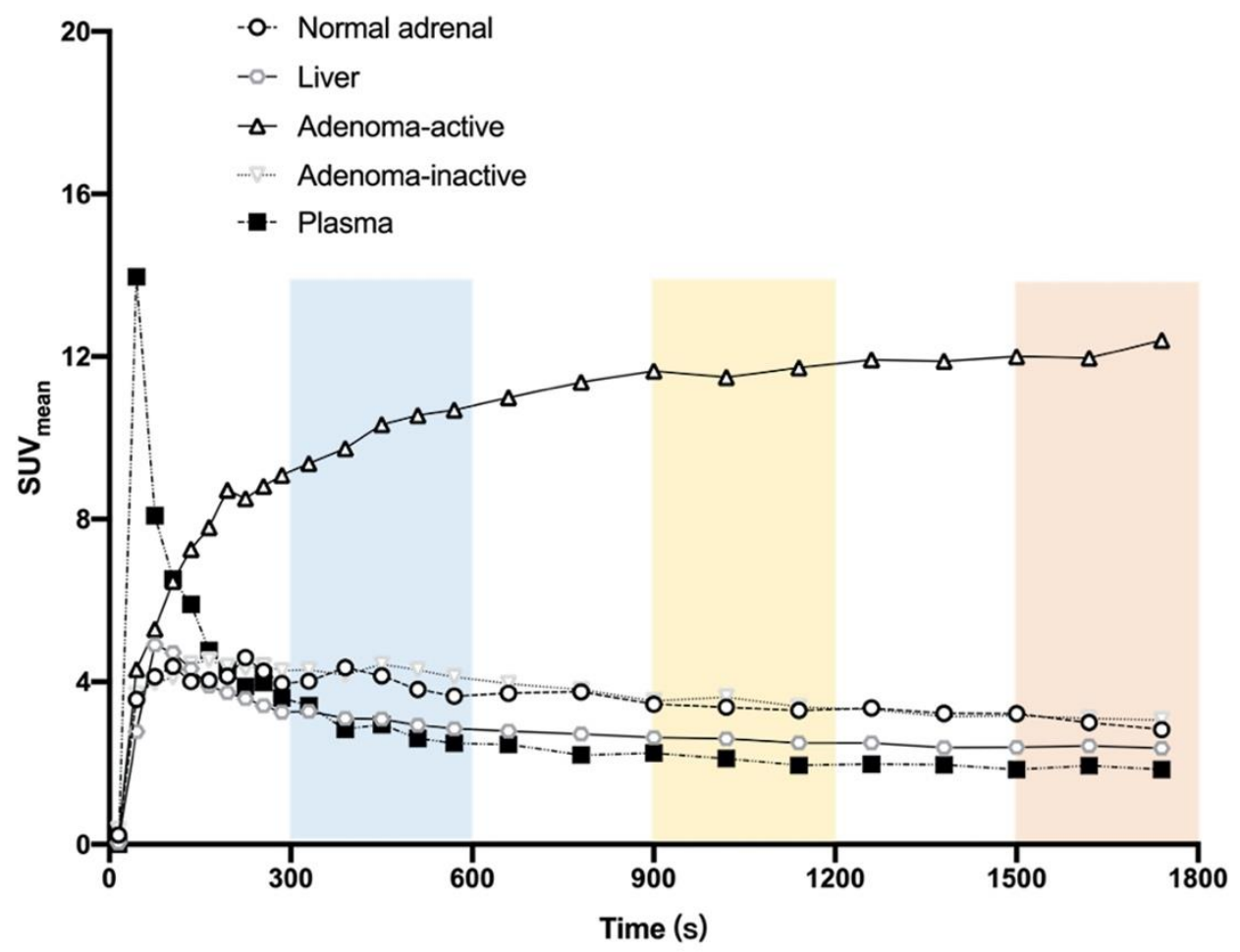

B

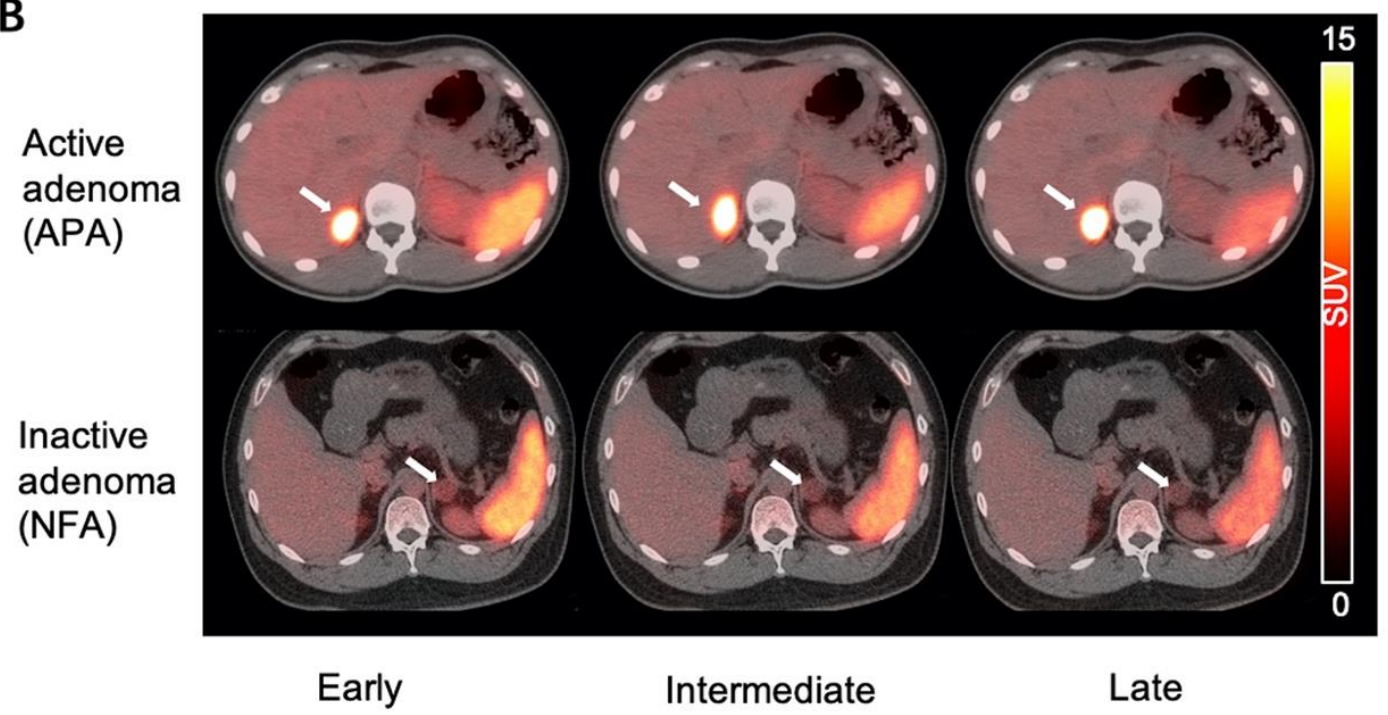

FIGURE 4. A. Time-activity curves of normal adrenal gland, liver, plasma, active adenomas, and inactive adenomas on ${ }^{68} \mathrm{Ga}$-pentixafor dynamic PET/CT scans (30 min). The spots represent the mean standard uptake values $\left(S U V_{\text {mean }}\right)$ at each time point. B. Representative ${ }^{68} \mathrm{Ga}$-pentixafor PET/CT scans in patients with an active adenoma (APA) and an inactive adenoma (NFA) at early (5-10 $\mathrm{min})$, intermediate (15-20 $\mathrm{min})$, and late (25-30 $\mathrm{min})$ time points. 

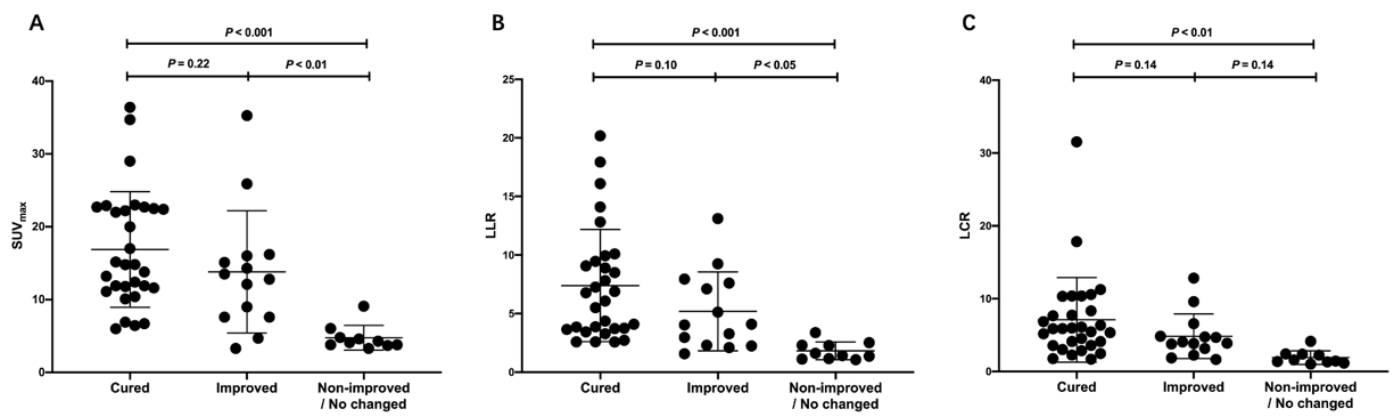

FIGURE 5. The maximum standard uptake value $\left(S U V_{\max }\right)(A)$, ratio of lesional $S U V_{\max }$ to normal liver SUVmean $(L L R)(B)$, and ratio of lesional SUV $\max$ to contralateral adrenal tissue SUV mean $(L C R)$ (C) of ${ }^{68}$ Ga-pentixafor in patients who were cured, improved, or nonimproved/no changed after adrenalectomy of adrenocortical lesions. In the cured, improved, and non-improved/no changed groups, the SUV $\max$ were $16.8 \pm 8.1,13.8 \pm 8.4$, and $4.8 \pm 1.7$; the LLRs were $7.4 \pm 4.8,5.2 \pm 3.4$, and $1.8 \pm 0.8$, and the LCRs were $7.1 \pm 5.0,4.8 \pm 3.1$, and $1.9 \pm 0.9$, respectively. 


\section{TABLES}

\section{TABLE 1 Baseline characteristics of 64 patients.}

\begin{tabular}{ll}
\hline Characteristics & Total $(\mathrm{n}=64)$ \\
\hline Age (years) & $47 \pm 10$ \\
Gender (male/female) & $33 / 31$ \\
BMI (kg/m²) & $25.3 \pm 3.3$ \\
Hypertension ( $\mathrm{n})$ & 53 \\
Refractory hypertension ( $\mathrm{n})$ & 20 \\
Duration of symptoms (years) & $7.4 \pm 6.1$ \\
Systolic pressure (mm Hg) & $175.0 \pm 29.4$ \\
Diastolic pressure (mm Hg) & $107.2 \pm 16.7$ \\
Serum potassium (mmol/L) & $2.9 \pm 0.9$ \\
ARR ([ng/dL]/[ng/mL/h]) & $151.8 \pm 66.7$ \\
Serum corticosteroid (ug/dL) & $15.7 \pm 5.8$ \\
ACTH (pg/ml) & $20.2(15.5-28.8)$ \\
24h-NE (ug/24hr) & $25.4 \pm 7.5$ \\
24h-UFC (ug/24hr) & $79.9(43.4-82.0)$ \\
Lesion location (right) & 24 \\
Lesion location (left) & 27 \\
Lesion location (bilateral) & 13 \\
\hline
\end{tabular}

ARR, aldosterone-renin ratio; BMI, body mass index; $\mathrm{ACTH}$, adreno-cortico-tropic-hormone;

NE, noradrenaline; UFC, urinary free cortisol. 
TABLE 2 Clinical diagnosis, treatments and the results of ${ }^{68} \mathrm{Ga}-\mathrm{Pentixafor}$ PET in all patients $(n=64)$.

\begin{tabular}{cccc}
\hline Primary diagnosis & Treatments & Final diagnosis & ${ }^{68} \mathrm{Ga}$-Pentixafor positive \\
\hline $46(\mathrm{APA})$ & $42 \mathrm{UA}, 1 \mathrm{BA}, 3 \mathrm{MT}$ & $40(\mathrm{APA})+3(\mathrm{sUAH})+3(\mathrm{IAH})$ & $39(\mathrm{APA})+3(\mathrm{sUAH})$ \\
$5(\mathrm{IAH})$ & $5 \mathrm{MT}$ & $5(\mathrm{IAH})$ & $1(\mathrm{IAH})$ \\
$3(\mathrm{CPA})$ & $2 \mathrm{UA}, 1 \mathrm{BA} ;$ & $3(\mathrm{CPA})$ & $3(\mathrm{CPA})$ \\
$9(\mathrm{NFA})$ & $9 \mathrm{UA}$ & $8(\mathrm{NFA})+1(\mathrm{PCC})$ & $1(\mathrm{NFA})$ \\
$1(\mathrm{PCC})$ & $1 \mathrm{UA}$ & $1(\mathrm{PCC})$ & 0 \\
\hline
\end{tabular}

Primary diagnosis was determined at baseline by endocrinologists and urologists based on clinical and imaging presentations. The final diagnosis was determined after treatment according to the diagnositic criteria listed in supplementary data. APA: Aldosterone-producing adenoma; IAH: Idiopathic aldosterone hyperplasia; sUAH: suspected unilateral adrenal hyperplasia; NFA: Nonfunctioning adrenal adenoma; CPA: Cortisol-producing adenoma; PCC: Pheochromocytoma; UA: unilateral adrenalectomy; BA: bilateral adrenalectomy: MT: medicine therapy 
TABLE 3 Imaging performance in 64 patients with 81 adrenal lesions.

\begin{tabular}{llllll}
\hline Lesions & $\begin{array}{l}\text { No. of } \\
\text { lesions }\end{array}$ & Length on CT $(\mathrm{cm})$ & SUV $_{\max }$ & LLR & LCR \\
\hline APA & 41 & $1.8 \pm 0.7$ & $15.3 \pm 7.7$ & $6.7 \pm 4.5$ & $5.6 \pm 3.3$ \\
SUAH & 5 & $1.1 \pm 0.4$ & $9.1 \pm 2.7$ & $2.7 \pm 0.7$ & $2.1 \pm 0.6$ \\
IAH & 15 & $1.3 \pm 0.5$ & $4.3 \pm 1.3$ & $1.4 \pm 0.5$ & $1.7 \pm 0.6$ \\
CPA & 4 & $2.5 \pm 0.7$ & $21.9 \pm 9.2$ & $7.3 \pm 2.3$ & $14.9 \pm 11.2$ \\
NFA & 14 & $1.9 \pm 0.8$ & $4.4 \pm 1.7$ & $1.7 \pm 0.7$ & $1.7 \pm 0.8$ \\
PCC & 2 & $1.6 ; 4.7$ & $1.7 ; 3.4$ & $0.3 ; 1.0$ & $1.7 ; 1.1$ \\
\hline
\end{tabular}

SUV $\max$, maximum standard uptake value LCR, ratio of lesional SUV $\max$ to contralateral adrenal tissue SUV mean; LLR, ratio of lesional SUV max $_{\text {to }}$ normal liver SUV mean; 
TABLE 4 Comparison of adrenal venous sampling and ${ }^{68}$ Ga-pentixafor PET/CT imaging results.

\begin{tabular}{|c|c|c|c|c|c|c|c|}
\hline \multirow{2}{*}{$\begin{array}{l}\text { Patient } \\
\text { NO. }\end{array}$} & \multicolumn{2}{|l|}{ AVS } & \multicolumn{4}{|c|}{${ }^{68} \mathrm{Ga}$-pentixafor PET/CT } & \multirow{2}{*}{$\begin{array}{l}\text { Clinical } \\
\text { Diagnosis }\end{array}$} \\
\hline & $\begin{array}{l}\text { Lateralızatıon } \\
\text { (Index) }\end{array}$ & $\begin{array}{l}\text { Selectivity } \\
\text { Index }\end{array}$ & Lateralization & SUV max & LLR & LCR & \\
\hline \#5 & Right (6.1) & $\begin{array}{l}30.8(\mathrm{~L}) \\
13.2(\mathrm{R})\end{array}$ & Right & 35.3 & 13.1 & 12.8 & $\begin{array}{l}\text { Right } \\
\text { APA }\end{array}$ \\
\hline \#34 & Bilateral (1.2) & $\begin{array}{l}5.4 \quad(\mathrm{~L}) \\
3.5(\mathrm{R})\end{array}$ & Left & 16.0 & 3.0 & 4.8 & Left APA \\
\hline \#39 & Left (62) & $\begin{array}{l}3.3(\mathrm{~L}) \\
22.6(\mathrm{R})\end{array}$ & Left & 7.6 & 2.2 & 3.2 & Left APA \\
\hline$\# 41$ & Left (6.1) & $\begin{array}{l}54.8(\mathrm{~L}) \\
31.5(\mathrm{R})\end{array}$ & Bilateral & 4.3 & 1.6 & 2.4 & $\mathrm{IAH}$ \\
\hline
\end{tabular}

Successful catheterization was defined as an adrenal vein/peripheral vein cortisol ratio (selectivity index) of $>3: 1$, and lateralization was defined as an aldosterone/cortisol ratio (lateralization index) of $>6: 1$ between the left and right adrenal veins. APA, aldosteroneproducing adenoma; AVS, adrenal venous sampling; IAH, idiopathic adrenal hyperplasia; LCR, ratio of lesional SUV max to contralateral adrenal tissue SUV mean; LLR, ratio of lesional SUV $\max$ to normal liver SUV mean; SUV $\max$, maximum standard uptake value 


\section{Supplement Materials}

\section{Diagnosis process and criteria (1)}

1. Differential diagnosis of benign or malignant tumors

Diagnoses were based on final pathology reports or stability on imaging for at least 12 months indicating a benign lesion.

\section{Hormone assessment}

Hormone assessments were made based on laboratory results as well as clinical documentation. A lesion was classified as nonfunctional if all laboratory studies were within normal range, and if the clinical history of the patient suggested that the lesion was nonfunctional. A lesion was classified as hormone producing if hormone production was specifically documented in the clinical history.

\section{The diagnosis criteria were:}

\section{APA (Aldosterone-producing adenoma):}

(1) The clinical diagnosis was suspected primary hyperaldosteronism with hypertension and/or hypokalemia.

(2) The laboratory tests showed an elevated plasma aldosterone-renin ratio (ARR) $(>30[\mathrm{ng} / \mathrm{dl}] /[\mathrm{ng} / \mathrm{ml} / \mathrm{h}])$ or a positive captopril challenge test (a decrease in plasma aldosterone level after captopril administration by $\leq 30 \%$ ).

(3) a. The postoperative pathology revealed an adrenocortical adenoma, and the patients were cured or improved clinically after adrenalectomy ( $>6$ months);

b. For those who did not undergo surgery: adrenal CT imaging revealed the typical features of an adenoma (homogeneous lesions with smooth margins; diameter $<2 \mathrm{~cm}$; the $\mathrm{CT}$ value $<10 \mathrm{HU}$ ) and no changes in symptoms and imaging during follow-up for at least 6 months.

\section{IAH (Idiopathic aldosterone hyperplasia or named Bilateral adrenal hyperplasia):}

(1) The clinical diagnosis was suspected primary hyperaldosteronism with hypertension and/or hypokalemia.

(2) The laboratory tests showed an elevated $\operatorname{ARR}(>30[\mathrm{ng} / \mathrm{dL}] /[\mathrm{ng} / \mathrm{mL} / \mathrm{h}])$ or a positive captopril challenge test (a decrease in plasma aldosterone level after captopril administration by $\leq 30 \%$ ). 
(3) a. The postoperative pathology revealed adrenocortical hyperplasia, and the patients improved or nonimproved by follow up after adrenalectomy (> 6 months);

b. adrenal CT showed bilateral/unilateral nodular thickening of the adrenals (single or multiple nodules), or thickened adrenals in patients who did not undergo surgery.

\section{suspected UAH (Unilateral adrenal hyperplasia):}

Recent research prompted UAH is not uncommon in patients with primary hyperaldosteronism (2).

(1) The clinical diagnosis was suspected primary hyperaldosteronism with hypertension and/or hypokalemia.

(2) The laboratory tests showed an elevated ARR $(>30[\mathrm{ng} / \mathrm{dL}] /[\mathrm{ng} / \mathrm{mL} / \mathrm{h}])$ or a positive captopril challenge test (a decrease in plasma aldosterone level after captopril administration by $\leq 30 \%$ ).

In our series, a diagnosis of UAH (sUAH) was only made when patients with PA were cured (follow up $>12$ months) after the unilateral adrenal nodular hyperplasia lesion was resected.

\section{CPA (Cortisol-producing adenoma):}

(1) The clinical diagnosis was independent Cushing's syndrome with typical features of cortisol excess, such as purple striae mainly located at the abdominal level, thin skin with easy bruising, and proximal muscle weakness.

(2) The laboratory tests showed decreased plasma adrenocorticotropic hormone (ACTH) concentration $(<10 \mathrm{pg} / \mathrm{mL})$ with overt endogenous hypercortisolism.

(3) The postoperative pathology revealed adrenocortical adenoma.

\section{NFA (Non-functioning adenoma):}

(1) The patients were symptom-free and the postoperative pathology of the adrenal lesion revealed an adrenocortical adenoma.

(2) The patients had hypertension with a normal biochemical test, and the postoperative pathology of the adrenal lesion revealed an adrenocortical adenoma.

(3) The patients had clinical symptoms with an elevated biochemical test that did not improve clinically and biochemically after resection of adrenocortical adenoma, which was confirmed by pathology. 
(4) Among PA patients with bilateral adrenal nodules, if the symptoms were alleviated through follow-up after one side of adenoma lesions were resected, the nodules on the contralateral side were assumed to be NFA lesions.

\section{PCC (Pheochromocytoma):}

The diagnosis was based on final pathology reports.

\section{Patient outcomes assessment criteria}

Clinical outcomes were assessed and compared in the 54 patients with adrenocortical lesions who underwent surgery. The time of follow-up was $>6$ months.

\section{For PA (primary hyperaldosteronism) patients:}

According to the criteria for assessment of final outcomes established by the Primary Aldosteronism Surgical Outcome study. the patients were categorized into three groups:

(1) Cured: normotensive blood pressure $<140 / 90 \mathrm{mmHg}$ after surgery, without the aid of antihypertensive medication or mineralocorticoid receptor (MR) antagonists along with a normal serum potassium level (normal range: $3.5-5.5 \mathrm{mmol} / \mathrm{L}$ in our hospital);

(2) Improved: blood pressure reduced or elevated serum potassium level, but not completely normalized with either the same or a lower amount of antihypertensive medication or mineralocorticoid receptor (MR) antagonists;

(3) Nonimproved: consistent or increased blood pressure and decreased serum potassium postoperatively, with either the same or an increased amount of antihypertensive medication or MR antagonists.

\section{For CS (Cushing's syndrome) patients:}

(1) Cured: Patients were considered biochemically cured after surgery if adrenal insufficiency was demonstrated or if the level of serum corticosteroid (normal range: 4.0-22.3 ug/dL), the serum ACTH concentrations (normal range: 10-46 pg/mL) and 24-h urinary free cortisol (UFC, normal range: 12.3-103.5 ug/24 h) measures were normal. The patients were also contacted by phone and asked to complete a CushingQoL questionnaire dealing with health perception, recovery of working ability, physical, psychological, social well-being status and so on after treatment ( $>6$ months) to confirm the clinical recovery (3). 
(2) Improved: The biochemical tests of the patients were improved, but not completely normalized.

(3) Nonimproved: The biochemical and clinical status of patients remained unchanged or was worse after surgery.

\section{For NFA patients:}

(1) Nonimproved: The NFA patients who also had essential hypertension had persistent symptoms after surgery.

(2) Not changed: The symptom-free NFA patients with had no symptoms after surgery.

\section{Reconstruction methods of dynamic PET imaging}

Dynamic images were reconstructed using the following scheme: $10 \times 30 \mathrm{~s}, 5 \times 60 \mathrm{~s}$, and $10 \times 120 \mathrm{~s}$, corrected for scatter, randoms, and attenuation. The mean standard uptake value $\left(\mathrm{SUV}_{\text {mean }}\right)$ for each frame was extracted from the volume of interest (VOI) of adrenal lesions, liver, the descending aorta, and normal adrenal tissue on dynamic imaging sequences to obtain time-activity curves (TACs). The dynamic parameters were calculated based on a two-tissue compartment model. Quantitative evaluation of dynamic PET data was performed using PMOD software (PMOD Technologies Ltd., Zürich, Switzerland). After compartmental analysis, the global influx (Ki) from compartment data was calculated using the formula $\mathrm{K} i=(\mathrm{K} 1 * \mathrm{k} 3) /(\mathrm{k} 2+\mathrm{k} 3)$. Besides, early, intermediate and late phase images were reconstructed and evaluated at 5-10min, 15-20min and 25-30min. In the 15 patients, static uptake was reconstructed and calculated during the last $5 \min (25-30 \mathrm{~min}$ after injection) of acquisition.

\section{The analysis of immunohistochemistry of CXCR4}

The intensity and amount of CXCR4-positive tumor cells in the immunoreaction were determined independently by a pathologist who was unaware of the clinical and imaging results. The percentage of tumor cells that were CXCR4 positive was scored as follows: $0 \%$, score 0 ; $0 \%-10 \%$, score 1 ; $10 \%-50 \%$, score $2 ; 50 \%-75 \%$, score 3 ; and $75 \%-100 \%$, score 4 . Intensities of staining were classified as follows: 0 (absent staining), 1 (low staining), 2 (intermediate staining), 3 (high staining). For each tumor, a value designated as the H score was than obtained by multiplying the intensity score by 
the percentage score. The H score was divided to three groups $(0-4,4-8$ and $8-12)$. The difference of ${ }^{68}$ Ga-pentixafor $\mathrm{SUV}_{\max }$ of the three groups were calculated.

\section{Supplement Results}

\section{The detailed clinical information was listed in supplemental table 1.}

Supplemental table 1. The detail characterization of the 64 patients.

\begin{tabular}{|c|c|c|c|c|c|c|c|c|c|c|c|c|c|c|c|c|c|c|c|c|c|c|c|c|c|c|c|}
\hline \multirow{2}{*}{$\begin{array}{c}\text { Patie } \\
\text { nt } \\
\text { NO.. }\end{array}$} & & \multirow{2}{*}{$\mathrm{Ige} \mathrm{Ser}$} & \multirow{2}{*}{$x=\begin{array}{c}\text { BMI } \\
(\mathrm{kg} / \mathrm{m} 2)\end{array}$} & \multirow{2}{*}{$\begin{array}{c}\text { Maximu } \\
\mathrm{m} \\
\text { systolic } \\
\text { pressure } \\
(\mathrm{mmHg})\end{array}$} & \multirow{2}{*}{$\begin{array}{c}\text { Maximu } \\
\mathrm{m} \\
\text { diastolic } \\
\text { pressure } \\
(\mathrm{mmHg})\end{array}$} & \multirow{2}{*}{$\begin{array}{c}\text { Duration of } \\
\text { Hypertension } \\
\text { (year) }\end{array}$} & \multirow{2}{*}{$\begin{array}{c}\begin{array}{c}\text { Serum } \\
\text { potassiu } \\
\mathrm{m} \\
(3.5-5.5 \\
\mathrm{mmol} / \mathrm{L})\end{array} \\
\end{array}$} & \multirow{2}{*}{$\begin{array}{c}\text { ARR } \\
([\mathrm{ng} / \mathrm{dl}] /[\mathrm{ng} / \mathrm{m} / \mathrm{h}])\end{array}$} & \multirow{2}{*}{$\begin{array}{c}\text { Serum } \\
\text { corticosteroid } \\
(4.0- \\
22.3 \mathrm{ug} / \mathrm{dL})\end{array}$} & \multirow{2}{*}{$\begin{array}{c}\text { ACTH } \\
(0-46 \mathrm{pg} / \mathrm{ml})\end{array}$} & \multirow{2}{*}{$\begin{array}{c}\text { 24h-NE } \\
(16.69-40.65 \\
\text { ug/24hr) }\end{array}$} & \multirow{2}{*}{$\mid \begin{array}{c}24 \mathrm{~h}-\text { UFC } \\
(12.3-103.5 \\
\text { ug/24hr) }\end{array}$} & \multirow{2}{*}{$\begin{array}{c}\text { Captopri } \\
1 \\
\text { test }\end{array}$} & \multirow{2}{*}{$\begin{array}{l}\text { Lesion } \\
\text { location }\end{array}$} & \multirow{2}{*}{$\mid \begin{array}{c}\text { Mass } \\
\text { diamete } \\
\mathrm{r} \\
(\mathrm{cm})\end{array}$} & \multirow{2}{*}{\multicolumn{2}{|c|}{\begin{tabular}{c|c}
$\mathrm{AV}$ & Diagnosis \\
$\mathrm{S}$ & before \\
$\mathrm{PET} / \mathrm{CT}$
\end{tabular}}} & \multicolumn{4}{|c|}{${ }^{68}$ Ga-pentixafor PET/CT } & \multirow{2}{*}{\begin{tabular}{|c} 
Primary \\
Diagnosis \\
before \\
treatment
\end{tabular}} & \multirow{2}{*}{ Management } & \multirow{2}{*}{$\begin{array}{l}\text { up, } \\
\text { mo }\end{array}$} & \multirow{2}{*}{$\begin{array}{c}\text { Outco } \\
\text { me }\end{array}$} & \multirow{2}{*}{$\begin{array}{c}\text { Final } \\
\text { diagnosi }\end{array}$} & \multirow{2}{*}{$s \mid \begin{array}{c}\text { Diagr } \\
\text { osis } \\
\text { ability } \\
\text { by } \\
\text { PET }\end{array}$} \\
\hline & & & & & & & & & & & & & & & & & & Lateralization & $S U V_{\text {max }}$ & LLR & LCR & & & & & & \\
\hline 1 & 51 & $\mathrm{~F}$ & 25.23 & 205 & 110 & 5 & 2.85 & 215.7 & 13.35 & 23.2 & 20.34 & 54.99 & + & $\mathrm{R}$ & 2.2 & 1 & APA(R) & $\mathrm{R}$ & 6.43 & 3.44 & 4.53 & $\mathrm{APA}(\mathrm{R})$ & $\begin{array}{c}\text { Right } \\
\text { adrenalectomy }\end{array}$ & 26 & Cured & d $A P A(R)$ & TP \\
\hline 2 & 39 & M & 28.7 & 185 & 130 & 2 & 3.8 & 69.4 & 15.51 & 19.6 & 33.19 & 97.28 & I & L & 1.8 & 1 & APA(L) & L & 22.7 & 16.1 & 5.97 & $\mathrm{APA}(\mathrm{L})$ & $\begin{array}{c}\text { Left } \\
\text { adrenalectomy }\end{array}$ & 27 & Cured & $\begin{array}{l}\mathrm{A} \\
\mathrm{APA}(\mathrm{L})\end{array}$ & TP \\
\hline 3 & 41 & M & 27.74 & 160 & 110 & 1 & 3 & 255.4 & 15.84 & 18.8 & 21.37 & 106.4 & 1 & L & 1 & 1 & APA(L) & L & 13.8 & 3.84 & 4.12 & $\mathrm{APA}(\mathrm{L})$ & $\begin{array}{c}\text { Left } \\
\text { adrenalectomy }\end{array}$ & 26 & Cured & $\begin{array}{l}\mathrm{A} \\
\mathrm{APA}(\mathrm{L})\end{array}$ & TP \\
\hline 4 & 46 & $\mathrm{~F}$ & 24.84 & 200 & 110 & 8 & 2.25 & 195.5 & 22.05 & 42.6 & 17.82 & 44.8 & + & $\mathrm{R}$ & 1.4 & 1 & APA(R) & $\mathrm{R}$ & 11.9 & 8.5 & 6.1 & $\mathrm{APA}(\mathrm{R})$ & $\begin{array}{c}\text { Right } \\
\text { adrenalectomy }\end{array}$ & 28 & Cured & $\begin{array}{l}d \\
A P A(R)\end{array}$ & $\mathrm{TP}$ \\
\hline 5 & 48 & M & 21.97 & 180 & 100 & 10 & 1.7 & 155 & 20.55 & 19.6 & 23.75 & 105.6 & - & B & $\begin{array}{l}\text { R:2; } \\
\text { L:0.9 }\end{array}$ & R & IAH & $\mathrm{R}$ & $\begin{array}{c}\text { R:35.27 } \\
; \\
\text { L:4.38 }\end{array}$ & $\begin{array}{l}\text { R:13.11; } \\
\text { L:1.63 }\end{array}$ & $\begin{array}{c}\text { R:12.8 } \\
3 ; \\
\text { L:1.59 }\end{array}$ & $A P A(R)$ & $\begin{array}{c}\text { Right } \\
\text { adrenalectomy }\end{array}$ & 26 & $\begin{array}{c}\text { Improv } \\
\text { ed }\end{array}$ & APA(R) & TP \\
\hline 6 & 38 & $\mathrm{~F}$ & 22.31 & 230 & 140 & 2 & 3.6 & 210.8 & 12.86 & 28.8 & I & 26.5 & + & L & 1.6 & 1 & APA(L) & L & 14.3 & 7.61 & 3.83 & $\operatorname{APA}(L)$ & Left & 25 & Improv & \begin{tabular}{l|l}
$v$ & $A P A(L)$
\end{tabular} & TP \\
\hline
\end{tabular}




\begin{tabular}{|c|c|c|c|c|c|c|c|c|c|c|c|c|c|c|c|c|c|c|c|c|c|c|c|c|c|c|c|}
\hline & & & & & & & & & & & & & & & & & & & & & & & adrenalectomy & & ed & & \\
\hline 7 & 38 & M & 29.4 & 189 & 126 & 1 & 2.8 & 213.3 & 18.97 & 23.9 & 20.46 & 1 & + & L & 1.4 & 1 & $\operatorname{APA}(\mathrm{L})$ & L & 15.16 & 3.64 & 6.34 & $\operatorname{APA}(L)$ & $\mid \begin{array}{c}\text { Left } \\
\text { adrenalectomy }\end{array}$ & 25 & Cured & APA $(L)$ & TP \\
\hline 8 & 44 & $\mathrm{~F}$ & 20.17 & 155 & 115 & 3 & 2.2 & 169.9 & 15.78 & 22.3 & 1 & 1 & - & L & 2.3 & 1 & APA(L) & L & 36.40 & 17.93 & 10.37 & $\operatorname{APA}(L)$ & $\begin{array}{c}\text { Left } \\
\text { adrenalectomy }\end{array}$ & 22 & Cured & APA $(L)$ & TP \\
\hline 9 & 31 & $\mathrm{~F}$ & 18.82 & 132 & 85 & 1 & 1.9 & 203.4 & 15.71 & 34.6 & 30 & 1 & + & $\mathrm{R}$ & 2.3 & 1 & $\operatorname{APA}(\mathrm{R})$ & $R$ & 23.0 & 20.18 & 17.83 & $\operatorname{APA}(R)$ & $\mid \begin{array}{c}\text { Right } \\
\text { adrenalectomy }\end{array}$ & 21 & Cured & $\operatorname{APA}(\mathrm{R})$ & TP \\
\hline 10 & 39 & $\mathrm{~F}$ & 23.44 & 200 & 120 & 8 & 2.2 & 154.3 & 12.23 & 28.6 & 24.25 & 58.8 & + & $\mathrm{R}$ & 1.8 & 1 & APA(R) & $R$ & 22.0 & 14.1 & 5.9 & $\operatorname{APA}(R)$ & $\begin{array}{c}\text { Right } \\
\text { adrenalectomy }\end{array}$ & 20 & Cured & APA(R) & TP \\
\hline 11 & 34 & M & 24.54 & 150 & 100 & 5 & 2.9 & 301.8 & 19.03 & 29.3 & 19.13 & 92.16 & + & $\mathrm{R}$ & 2.9 & 1 & APA(R) & $R$ & 29.0 & 6.78 & 8.33 & $\operatorname{APA}(\mathrm{R})$ & $\begin{array}{c}\text { Right } \\
\text { adrenalectomy }\end{array}$ & 22 & Cured & APA(R) & TP \\
\hline 12 & 63 & $\mathrm{~F}$ & 24.22 & 170 & 105 & 19 & 4 & 93.8 & 10.82 & 1 & 1 & 80.96 & 1 & L & 2.6 & 1 & NFA & $R$ & 13.5 & 4.03 & $\mid 4.67$ & $\operatorname{APA}(\mathrm{R})$ & $\begin{array}{c}\text { Right } \\
\text { adrenalectomy }\end{array}$ & 23 & $\begin{array}{c}\text { Improv } \\
\text { ed }\end{array}$ & APA(R) & TP \\
\hline 13 & 56 & $\mathrm{~F}$ & 22.23 & 200 & 110 & 11 & 2.4 & 217.8 & 15.61 & 1 & 1 & 1 & + & L & 1.3 & 1 & APA(L) & L & 22.4 & 9.08 & 5.45 & $\operatorname{APA}(L)$ & $\begin{array}{c}\text { Left } \\
\text { adrenalectomy }\end{array}$ & 21 & Cured & APA(L) & TP \\
\hline 14 & 55 & $\mathrm{~F}$ & 21.64 & 200 & 100 & 20 & 1.6 & 169.6 & 1 & 30.4 & 19.79 & 55.88 & + & L & 1.9 & 1 & $\operatorname{APA}(\mathrm{L})$ & L & 10.4 & 3.71 & 3.59 & $\operatorname{APA}(L)$ & $\begin{array}{c}\text { Left } \\
\text { adrenalectomy }\end{array}$ & 20 & Cured & APA $(L)$ & TP \\
\hline 15 & 42 & $\mathrm{~F}$ & 21.13 & 197 & 120 & 0.5 & 2.4 & 119.1 & 15.91 & 31.6 & 17.55 & 38.8 & + & $\mathrm{R}$ & 1.1 & 1 & APA(R) & $R$ & 11.1 & 4.1 & 3.01 & $\operatorname{APA}(R)$ & $\begin{array}{c}\text { Right } \\
\text { adrenalectomy }\end{array}$ & 22 & Cured & APA(R) & TP \\
\hline 16 & 34 & M & 30.49 & 180 & 130 & 5 & 1.4 & 116.3 & 5.6 & 10.9 & 31.83 & 87.77 & + & B & $\begin{array}{l}\text { R: 2.2; } \\
\text { L:0.7 }\end{array}$ & 1 & $\operatorname{APA}(\mathrm{R})$ & $\mathrm{R}$ & 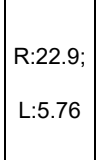 & $\begin{array}{l}\text { R:7.82; } \\
\text { L:1.97 }\end{array}$ & \begin{tabular}{|l} 
R:5.3 \\
$4 ;$ \\
L:1.34
\end{tabular} & $\operatorname{APA}(R)$ & $\mid \begin{array}{c}\text { Right } \\
\text { adrenalectomy }\end{array}$ & 25 & Cured & APA(R) & TP \\
\hline 17 & 52 & M & 25.06 & 190 & 110 & 5 & 1.7 & 179.5 & 20.13 & 24.1 & 1 & 62 & + & $\mathrm{R}$ & 2.1 & 1 & APA(R) & $R$ & 10.1 & 2.59 & 5.87 & $\operatorname{APA}(R)$ & $\begin{array}{c}\text { Right } \\
\text { adrenalectomy }\end{array}$ & 24 & Cured & APA(R) & TP \\
\hline 18 & 46 & $\mathrm{~F}$ & 23.63 & 180 & 100 & 18 & 2 & 200 & 13.97 & 15.7 & 1 & 75.81 & + & L & 3.5 & 1 & $\operatorname{APA}(L)$ & L & 14.8 & 9.93 & 6.85 & $\operatorname{APA}(L)$ & $\mid \begin{array}{c}\text { Left } \\
\text { adrenalectomy }\end{array}$ & 23 & Cured & APA(L) & TP \\
\hline
\end{tabular}




\begin{tabular}{|c|c|c|c|c|c|c|c|c|c|c|c|c|c|c|c|c|c|c|c|c|c|c|c|c|c|c|c|}
\hline 19 & 53 & $\mathrm{~F}$ & 24.56 & 180 & 110 & 12 & 3 & 127.8 & 1 & 23.6 & 18.18 & 1 & + & $\mathrm{R}$ & 1.5 & 1 & APA(R) & $\mathrm{R}$ & 13.2 & 5.5 & 3.57 & $\mathrm{APA}(\mathrm{R})$ & $\begin{array}{c}\text { Right } \\
\text { adrenalectomy }\end{array}$ & 24 & Cured & APA(R) & TP \\
\hline 20 & 45 & $\mathrm{~F}$ & 25.39 & 200 & 100 & 15 & 1.6 & 116.2 & 2.29 & 41.4 & 22.15 & 63.36 & + & $\mathrm{R}$ & 2.3 & 1 & APA(R) & $\mathrm{R}$ & 17.0 & 6.07 & 7.73 & $\operatorname{APA}(\mathrm{R})$ & $\begin{array}{c}\text { Right } \\
\text { adrenalectomy }\end{array}$ & 21 & Cured & APA(R) & TP \\
\hline 21 & 41 & M & 24.9 & 180 & 110 & 4 & 3.1 & 129.5 & 13.75 & 14 & 1 & 107.6 & + & L & 1.3 & 1 & APA(L) & $\mathrm{L}$ & 6.7 & 2.58 & 1.76 & $\operatorname{APA}(L)$ & $\begin{array}{c}\text { Left } \\
\text { adrenalectomy }\end{array}$ & 20 & Cured & APA $(L)$ & TP \\
\hline 22 & 55 & M & 25.95 & 160 & 110 & 10 & 2.5 & 150.4 & 10.9 & 13.4 & 24 & 66.4 & I & B & $\begin{array}{l}\text { R:2.6; } \\
\text { L:2.1 }\end{array}$ & 1 & Unknown & $\mathrm{R}$ & $\begin{array}{l}\text { R:22.5; } \\
\text { L:4.38 }\end{array}$ & $\begin{array}{l}\text { R:7.26; } \\
\text { L:1.1.63 }\end{array}$ & $\mid \begin{array}{c}\text { R:11.2 } \\
5 ; \\
\text { L:1.59 }\end{array}$ & $\mathrm{APA}(\mathrm{R})$ & $\mid \begin{array}{c}\text { Right } \\
\text { adrenalectomy }\end{array}$ & 19 & Cured & APA(R) & TP \\
\hline 23 & 43 & $\mathrm{M}$ & 28.04 & 180 & 110 & 10 & 2.7 & 280.8 & 12.6 & 36.3 & 1 & 83 & 1 & $\mathrm{R}$ & 1.6 & 1 & IAH & $\mathrm{R}$ & 9.0 & 4.09 & 4.74 & $\mathrm{APA}(\mathrm{R})$ & $\begin{array}{c}\text { Right } \\
\text { adrenalectomy }\end{array}$ & 23 & $\begin{array}{c}\text { Improv } \\
\text { ed }\end{array}$ & APA(R) & TP \\
\hline 24 & 30 & $F$ & 19.2 & 220 & 130 & 1 & 2.3 & 172.8 & 13.7 & 35.9 & 37.2 & 45.8 & + & $\mathrm{R}$ & 3.8 & 1 & APA $(R)$ & $\mathrm{R}$ & 25.9 & 9.25 & 9.59 & $\operatorname{APA}(R)$ & $\mid \begin{array}{c}\text { Right } \\
\text { adrenalectomy }\end{array}$ & 22 & $\begin{array}{c}\text { Improv } \\
\text { ed }\end{array}$ & APA(R) & TP \\
\hline 25 & 28 & $F$ & 25.97 & 240 & 140 & 2 & 2.6 & 119.4 & 9.7 & 24.4 & 30.41 & 30 & + & $\mathrm{R}$ & 1.7 & 1 & APA(R) & $\mathrm{R}$ & 22.2 & 10.09 & 7.66 & $\operatorname{APA}(\mathrm{R})$ & $\mid \begin{array}{c}\text { Right } \\
\text { adrenalectomy }\end{array}$ & 17 & Cured & APA(R) & TP \\
\hline 26 & 45 & $F$ & 21.36 & 220 & 110 & 0.5 & 2.6 & 154.6 & 15.8 & 28.8 & 1 & 10 & + & $\mathrm{L}$ & 1.7 & 1 & APA(L) & $\mathrm{L}$ & 16.2 & 7.11 & 4.07 & $\operatorname{APA}(L)$ & $\begin{array}{c}\text { Left } \\
\text { adrenalectomy }\end{array}$ & 17 & $\begin{array}{c}\text { Improv } \\
\text { ed }\end{array}$ & APA(L) & TP \\
\hline 27 & 47 & M & 22.99 & 180 & 110 & 6 & 1.39 & 175.4 & 13.2 & 25.7 & 30.41 & 54.5 & + & L & 2.4 & 1 & APA(L) & L & 20.0 & 12.82 & 10.36 & $\operatorname{APA}(L)$ & $\mid \begin{array}{c}\text { Left } \\
\text { adrenalectomy }\end{array}$ & 19 & Cured & APA(L) & TP \\
\hline 28 & 37 & $\mathrm{M}$ & 30.42 & 180 & 120 & 1 & 3.3 & 102.9 & 18.6 & 15.7 & 1 & 48.8 & + & B & $\begin{array}{l}\text { L:1.8; } \\
\text { R:0.8 }\end{array}$ & 1 & IAH & B & \begin{tabular}{|c|} 
L:12.8; \\
R:7.2 \\
\end{tabular} & $\begin{array}{l}\text { L:5.12; } \\
\text { R:2.88 }\end{array}$ & $\begin{array}{l}\text { L:3.8.8; } \\
\text { R:2.18 }\end{array}$ & $\mathrm{APA}(\mathrm{B})$ & $\begin{array}{c}\text { Bilateral } \\
\text { adrenalectomy }\end{array}$ & 17 & $\begin{array}{c}\text { Improv } \\
\text { ed }\end{array}$ & APA(B) & TP \\
\hline 29 & 53 & $F$ & 24.68 & 150 & 100 & 6 & 3.9 & 145.2 & 18.8 & 27.8 & 15.36 & 51.5 & I & B & $\begin{array}{l}\mathrm{R}: 2.2 ; \\
\mathrm{L}: 0.8\end{array}$ & 1 & APA $(R)$ & $\mathrm{R}$ & \begin{tabular}{|l|} 
L:6.0; \\
R:2.2 \\
\end{tabular} & $\begin{array}{l}\text { L:3.75; } \\
\text { R:1.0 }\end{array}$ & $\begin{array}{l}\text { L:2.86; } \\
\text { R:0.85 }\end{array}$ & $\operatorname{APA}(R)$ & $\mid \begin{array}{c}\text { Right } \\
\text { adrenalectomy }\end{array}$ & 17 & Cured & APA(R) & TP \\
\hline 30 & 51 & M & 24.34 & 180 & 110 & 14 & 2.2 & 150.6 & 16.8 & 21.3 & 1 & 99.1 & + & $\mathrm{R}$ & 1.5 & 1 & APA(R) & $\mathrm{R}$ & 11.9 & 2.59 & 5.17 & $\operatorname{APA}(R)$ & $\mid \begin{array}{c}\text { Right } \\
\text { adrenalectomy }\end{array}$ & 16 & Cured & APA(R) & TP \\
\hline 31 & 48 & M & 28.41 & 180 & 130 & 13 & 1.8 & 158.2 & 6.5 & 15.4 & 29.27 & 70.8 & + & $\mathrm{R}$ & 0.6 & 1 & APA(R) & $\mathrm{N}$ & 4.7 & 1.57 & 2.24 & $\operatorname{APA}(R)$ & Right & 19 & Improv & APA(R) & $\mathrm{FN}$ \\
\hline
\end{tabular}




\begin{tabular}{|c|c|c|c|c|c|c|c|c|c|c|c|c|c|c|c|c|c|c|c|c|c|c|c|c|c|c|c|}
\hline & & & & & & & & & & & & & & & & & & & & & & & adrenalectomy & & ed & & \\
\hline 32 & 52 & M & 27.02 & 170 & 100 & 10 & 2.5 & 195.7 & 1 & 14.8 & 25.9 & 53.6 & + & L & 1.3 & 1 & APA $(L)$ & L & 12.1 & 3.27 & 3.78 & $\mathrm{APA}(\mathrm{L})$ & $\mid \begin{array}{c}\text { Left } \\
\text { adrenalectomy }\end{array}$ & 15 & $\begin{array}{c}\text { Improv } \\
\text { ed }\end{array}$ & APA(L) & TP \\
\hline 33 & 70 & M & 24.02 & 186 & 107 & 8 & 2.8 & 131.8 & 15.5 & 20.9 & 1 & 37.8 & + & B & $\begin{array}{l}\text { L:1.1; } \\
\text { R:0.6 }\end{array}$ & 1 & APA(L) & L & $\begin{array}{l}\text { L:12.2; } \\
\text { R:3.7 }\end{array}$ & $\begin{array}{l}\text { L:5.55; } \\
\text { R:1.19 }\end{array}$ & $\begin{array}{l}\text { L:4.69; } \\
\text { R:1.85 }\end{array}$ & $\operatorname{APA}(\mathrm{L})$ & 1 & 24 & 1 & APA(L) & TP \\
\hline 34 & 46 & F & 23.88 & 190 & 100 & 8 & 1 & 176.1 & 22 & 19.1 & 1 & 52.75 & - & B & $\begin{array}{l}\text { L:1.9; } \\
\text { R:0.8 }\end{array}$ & $\mathrm{N}$ & IAH & $\mathrm{L}$ & $\begin{array}{c}\text { L:16.0; } \\
\text { R:3.1 }\end{array}$ & $\begin{array}{l}\text { L:2.96; } \\
\text { R:1.03 }\end{array}$ & $\begin{array}{l}\text { L:4.85; } \\
\text { R:1.29 }\end{array}$ & $\operatorname{APA}(L)$ & $\mid \begin{array}{c}\text { Left } \\
\text { adrenalectomy }\end{array}$ & 20 & $\begin{array}{c}\text { Improv } \\
\text { ed }\end{array}$ & APA(L) & TP \\
\hline 35 & 46 & M & 25.95 & 170 & 110 & 10 & 2 & 150 & 15.45 & 16 & 34.88 & 66.58 & + & $\mathrm{R}$ & 1.9 & 1 & APA $(R)$ & $\mathrm{R}$ & 15.1 & 7.95 & 6.57 & $\mathrm{APA}(\mathrm{R})$ & $\begin{array}{c}\text { Right } \\
\text { adrenalectomy }\end{array}$ & 19 & $\begin{array}{c}\text { Improv } \\
\text { ed }\end{array}$ & APA $(R)$ & TP \\
\hline 36 & 55 & $\mathrm{~F}$ & 20.45 & 150 & 90 & 2 & 4.2 & 137.7 & 1 & 14.7 & 1 & 1 & 1 & $\mathrm{~L}$ & 1.9 & 1 & APA(L) & $\mathrm{L}$ & 7.7 & 3.5 & 2.2 & APA(L) & 1 & 28 & 1 & APA(L) & TP \\
\hline 37 & 47 & F & 27.68 & 170 & 95 & 5 & 2.7 & 141 & 20 & 35.8 & 1 & 72 & + & L & 1.3 & 1 & APA(L) & L & 11.6 & 3.87 & 2.47 & $\mathrm{APA}(\mathrm{L})$ & $\mid \begin{array}{c}\text { Left } \\
\text { adrenalectomy }\end{array}$ & 25 & Cured & APA(L) & TP \\
\hline 38 & 42 & $\mathrm{~F}$ & 22.1 & 180 & 110 & 6 & 3.2 & 151.5 & 6.1 & 15.3 & 39.16 & 10 & + & $R$ & 1.1 & 1 & APA(R) & $\mathrm{R}$ & 8.3 & 3.61 & 1.54 & $\mathrm{APA}(\mathrm{R})$ & I & 25 & I & APA(R) & TP \\
\hline 39 & 51 & M & 26.54 & 160 & 130 & 6 & 1.7 & 216.6 & 15.37 & 20.3 & 1 & 1 & + & L & 1.4 & L & APA(L) & $\mathrm{L}$ & 7.6 & 2.24 & 3.17 & $\operatorname{APA}(L)$ & $\begin{array}{c}\text { Left } \\
\text { adrenalectomy }\end{array}$ & 22 & $\begin{array}{c}\text { Improv } \\
\text { ed }\end{array}$ & APA(L) & TP \\
\hline 40 & 57 & M & 26.57 & 190 & 110 & 10 & 2.6 & 188.3 & 14 & 18.7 & 1 & 1 & + & $\mathrm{R}$ & 1.9 & 1 & APA $(R)$ & $\mathrm{R}$ & 7.6 & 2.78 & 2.20 & APA $(R)$ & $\begin{array}{c}\text { Right } \\
\text { adrenalectomy }\end{array}$ & 20 & $\begin{array}{c}\text { Improv } \\
\text { ed }\end{array}$ & APA $(R)$ & TP \\
\hline 41 & 44 & F & 23.42 & 150 & 100 & 12 & 2.8 & 168 & 21.6 & 16.6 & 21.57 & 54.4 & I & L & 1.7 & 1 & APA(L) & $\mathrm{L}$ & 11.8 & 2.72 & 2.25 & $\operatorname{APA}(L)$ & $\begin{array}{c}\text { Left } \\
\text { adrenalectomy }\end{array}$ & 17 & Cured & $\mathrm{sUAH}(\mathrm{L})$ & TP \\
\hline 42 & 48 & F & 19.98 & 180 & 90 & 0.5 & 2.8 & 112.1 & 1 & 24.8 & 1 & 1 & 1 & $\mathrm{R}$ & 0.7 & 1 & APA $(R)$ & $\mathrm{R}$ & 6.9 & 3.28 & 1.69 & APA $(R)$ & $\begin{array}{c}\text { Right } \\
\text { adrenalectomy }\end{array}$ & 19 & Cured & $\operatorname{s\cup AH}(R)$ & TP \\
\hline 43 & 60 & F & 22.59 & 180 & 100 & 20 & 2.15 & 160.1 & 23.1 & 19.1 & I & 43.2 & + & L & $0.8-1.5$ & 1 & APA $(L)$ & L & $6.7-12.4$ & 3.54 & 3.14 & $\mathrm{APA}(\mathrm{L})$ & $\begin{array}{c}\text { Left } \\
\text { adrenalectomy }\end{array}$ & 22 & Cured & $\mathrm{sUAH}(\mathrm{L})$ & TP \\
\hline 44 & 26 & M & 28.01 & 225 & 130 & 1 & 2.7 & 19.9 & 1 & I & 1 & 46.2 & 1 & L & 1 & 1 & APA(L) & $\mathrm{N}$ & 4.8 & 1.12 & 1.37 & $\mathrm{APA}(\mathrm{L})$ & $\begin{array}{c}\text { Left } \\
\text { adrenalectomy }\end{array}$ & 27 & $\begin{array}{l}\text { Nonimp } \\
\text { roved }\end{array}$ & IAH & TN \\
\hline 45 & 46 & M & 31.28 & 220 & 135 & 11 & 2.6 & 245.2 & 9.97 & 48.4 & 38.44 & 42.56 & + & L & 1.5 & L & APA(L) & $\mathrm{N}$ & 4.3 & 1.61 & 2.39 & $\mathrm{APA}(\mathrm{L})$ & Left & 18 & Nonimp & IAH & TN \\
\hline
\end{tabular}




\begin{tabular}{|c|c|c|c|c|c|c|c|c|c|c|c|c|c|c|c|c|c|c|c|c|c|c|c|c|c|c|c|}
\hline & & & & & & & & & & & & & & & & & & & & & & & adrenalectomy & & roved & & \\
\hline 46 & 59 & $F$ & 28.04 & 200 & 110 & 20 & 4.1 & 185.3 & 20.19 & 16.7 & 16.63 & 46.1 & 1 & L & 1.5 & 1 & APA $(L)$ & $\mathrm{N}$ & 3.3 & 2.09 & 1.65 & $\operatorname{APA}(L)$ & $\mid \begin{array}{c}\text { Left } \\
\text { adrenalectomy }\end{array}$ & 27 & $\begin{array}{c}\text { Improv } \\
\text { ed }\end{array}$ & IAH & TN \\
\hline 47 & 60 & M & 29.91 & 153 & 91 & 2 & 4.3 & 250.8 & 23.58 & 61.3 & 24.38 & 58.91 & + & L & 0.9 & 1 & APA(L) & $\mathrm{N}$ & 3.2 & 1.45 & 1.39 & IAH & 1 & 25 & 1 & IAH & TN \\
\hline 48 & 61 & M & 27.55 & 160 & 100 & 4 & 2.4 & 160.3 & 30.2 & 33.1 & l & 90.4 & + & L & $|0.8-1.0|$ & 1 & IAH & $\mathrm{N}$ & $4.2-4.8$ & 2.0-2.29 & $\begin{array}{c}1.56- \\
1.78\end{array}$ & IAH & 1 & 28 & I & IAH & TN \\
\hline 49 & 54 & M & 29.41 & 180 & 120 & 18 & 1.9 & 218.3 & 16.3 & 26.4 & 1 & 1 & 1 & B & \begin{tabular}{|l|} 
L:1.1; \\
R:0.9 \\
\end{tabular} & 1 & IAH & $\mathrm{L}$ & \begin{tabular}{|l|} 
L:7.6; \\
R:4.2 \\
\end{tabular} & $\begin{array}{l}\text { L:1.33; } \\
\text { R:0.73 }\end{array}$ & $\begin{array}{l}: 1.46 ; \\
R: 0.81 \\
\end{array}$ & IAH & 1 & 34 & 1 & IAH & FP \\
\hline 50 & 55 & M & 32.95 & 230 & 150 & 10 & 2.2 & 318.7 & 1 & 1 & 26.53 & 43.68 & 1 & B & $\mid 0.9-1.2$ & 1 & IAH & $\mathrm{N}$ & $3.2-5.5$ & $0.8-1.45$ & \begin{tabular}{|l|}
$1.68-$ \\
2.89
\end{tabular} & IAH & 1 & 25 & 1 & IAH & TN \\
\hline 51 & 57 & M & 25.95 & 200 & 120 & 20 & 3.2 & 50.3 & 14.15 & 7.1 & 32.59 & 56.16 & - & B & $\mid 1.1-2.5$ & 1 & IAH & $\mathrm{N}$ & \begin{tabular}{|l|} 
\\
\end{tabular} & $\begin{array}{l}0.57- \\
1.24\end{array}$ & \begin{tabular}{|l|}
$0.71-$ \\
1.92 \\
\end{tabular} & IAH & 1 & 25 & I & IAH & TN \\
\hline 52 & 63 & $\mathrm{M}$ & 24.49 & 186 & 110 & 5 & 3.6 & 116.5 & 23.14 & 53.7 & 17.4 & 34.8 & - & L & 1.4 & 1 & APA(L) & $\mathrm{N}$ & 3.7 & 1.16 & 1.03 & $\operatorname{NFA}(L)$ & $\mid \begin{array}{c}\text { Left } \\
\text { adrenalectomy }\end{array}$ & 17 & $\begin{array}{c}\text { Nonimp } \\
\text { roved }\end{array}$ & NFA(L) & $\mathrm{TN}$ \\
\hline 53 & 66 & $F$ & 27.24 & 140 & 90 & 1 & 3.7 & 103.4 & 10.43 & 7.5 & 41.15 & 23.2 & 1 & $\mathrm{R}$ & 3.0 & 1 & NFA(R) & $\mathrm{N}$ & 3.8 & 1.41 & 2.24 & $\operatorname{NFA}(R)$ & $\mid \begin{array}{c}\text { Right } \\
\text { adrenalectomy }\end{array}$ & 25 & $\begin{array}{c}\text { No } \\
\text { change }\end{array}$ & NFA(R) & TN \\
\hline 54 & 52 & $F$ & 24.77 & 128 & 86 & 1 & 3.7 & 129.5 & 9.41 & 20 & 19.37 & 91.6 & 1 & $\mathrm{R}$ & 2.8 & 1 & NFA(R) & $\mathrm{N}$ & 4.6 & 2.3 & 2.42 & $\operatorname{NFA}(R)$ & $\begin{array}{c}\text { Right } \\
\text { adrenalectomy }\end{array}$ & 26 & \begin{tabular}{c|} 
No \\
change
\end{tabular} & NFA(R) & TN \\
\hline 55 & 55 & $F$ & 18.87 & 136 & 89 & 1 & 4.6 & 12.5 & 1 & 15.6 & 21.74 & 47.88 & I & L & 2.4 & 1 & NFA(L) & $\mathrm{N}$ & 6.0 & 2.51 & 1.59 & $\operatorname{NFA}(L)$ & $\begin{array}{c}\text { Left } \\
\text { adrenalectomy }\end{array}$ & 35 & $\begin{array}{c}\text { No } \\
\text { change }\end{array}$ & NFA(L) & TN \\
\hline 56 & 44 & M & 23.53 & 139 & 92 & 1 & 4.6 & 70.9 & 21.41 & 13.4 & 25.81 & 79.8 & 1 & L & 2.2 & 1 & NFA(L) & $\mathrm{N}$ & 3.3 & 1.06 & 1.43 & $\operatorname{NFA}(L)$ & $\mid \begin{array}{c}\text { Left } \\
\text { adrenalectomy }\end{array}$ & 25 & \begin{tabular}{c|} 
No \\
change
\end{tabular} & NFA(L) & TN \\
\hline 57 & 55 & $F$ & 24.46 & 115 & 72 & 1 & 3.7 & 145.7 & 1 & 8.2 & 27.47 & 37.1 & 1 & $\mathrm{R}$ & 2.7 & 1 & NFA(R) & $\mathrm{R}$ & 9.1 & 3.37 & 3.14 & $\mathrm{NFA}(\mathrm{R})$ & $\begin{array}{c}\text { Right } \\
\text { adrenalectomy }\end{array}$ & 25 & $\begin{array}{c}\text { No } \\
\text { change }\end{array}$ & NFA(R) & FP \\
\hline 58 & 36 & M & 30.39 & 160 & 110 & 0.5 & 4.1 & 1.8 & 1 & 16.3 & 1 & 1 & 1 & L & 2.9 & 1 & NFA(L) & $\mathrm{N}$ & 3.8 & 1.36 & 1.15 & $\operatorname{NFA}(L)$ & $\mid \begin{array}{c}\text { Left } \\
\text { adrenalectomy }\end{array}$ & 20 & $\begin{array}{c}\text { Nonimp } \\
\text { roved }\end{array}$ & NFA(L) & TN \\
\hline
\end{tabular}




\begin{tabular}{|c|c|c|c|c|c|c|c|c|c|c|c|c|c|c|c|c|c|c|c|c|c|c|c|c|c|c|c|}
\hline 59 & 42 & $\mathrm{~F}$ & 30.09 & 128 & 82 & 1 & 4.6 & 72.1 & 8.5 & 1 & 35.4 & 58 & 1 & L & 2.0 & 1 & NFA(L) & $\mathrm{N}$ & 4.1 & 2.28 & 1.37 & $\operatorname{NFA}(L)$ & $\mid \begin{array}{c}\text { Left } \\
\text { adrenalectomy }\end{array}$ & 14 & $\begin{array}{c}\text { No } \\
\text { change }\end{array}$ & NFA & TN \\
\hline 60 & 36 & $\mathrm{~F}$ & 24.91 & 140 & 90 & 1 & 4.4 & 92 & 25.01 & $<5$ & 7.79 & 346.5 & 1 & $\mathrm{R}$ & 1.9 & 1 & $\mathrm{CPA}(\mathrm{R})$ & $\mathrm{R}$ & 14.8 & 4.36 & 10.58 & $\mathrm{CPA}(\mathrm{R})$ & $\begin{array}{c}\text { Right } \\
\text { adrenalectomy }\end{array}$ & 26 & Cured & $\mathrm{CPA}(\mathrm{R})$ & TP \\
\hline 61 & 40 & $\mathrm{~F}$ & 25.39 & 142 & 74 & 1 & 4.2 & 1 & 25.64 & $<5$ & 1 & 383.95 & 1 & $\mathrm{R}$ & 3.3 & 1 & CPA(R) & $\mathrm{R}$ & 34.7 & 8.9 & 31.55 & $\mathrm{CPA}(\mathrm{R})$ & $\begin{array}{c}\text { Right } \\
\text { adrenalectomy }\end{array}$ & 25 & Cured & CPA(R) & TP \\
\hline 62 & 37 & $\mathrm{~F}$ & 31.14 & 137 & 90 & I & 4.2 & 153.2 & 22.7 & $<5$ & 24.88 & 592.3 & I & B & $\begin{array}{l}\text { L:2.9 } \\
\text { R:1.6 }\end{array}$ & 1 & Unknown & B & $\begin{array}{l}\text { L:22.7; } \\
\text { R:15.5 }\end{array}$ & $\begin{array}{l}\text { L:9.46; } \\
\text { R:6.46 }\end{array}$ & $\mid \begin{array}{c}\text { L:10.3 } \\
\text { 2; } \\
\text { R:7.05 }\end{array}$ & $\mathrm{CPA}(\mathrm{B})$ & $\begin{array}{c}\text { Bilateral } \\
\text { adrenalectomy }\end{array}$ & 18 & Cured & $\mathrm{CPA}(\mathrm{B})$ & TP \\
\hline 63 & 40 & M & 24.22 & 101 & 74 & 1 & 4.0 & 49.8 & 6.18 & 19 & 19.87 & 30.24 & 1 & L & 1.6 & 1 & NFA(L) & $\mathrm{N}$ & 1.7 & 0.31 & 1.7 & $\operatorname{NFA}(L)$ & $\begin{array}{c}\text { Left } \\
\text { adrenalectomy }\end{array}$ & 20 & $\begin{array}{c}\text { No } \\
\text { change }\end{array}$ & $P C C(L)$ & TN \\
\hline 64 & 55 & $\mathrm{~F}$ & 23.31 & 150 & 90 & 0.5 & 3.9 & 11.5 & 10.4 & 22.4 & 32.33 & 18.96 & 1 & $\mathrm{R}$ & 4.0 & 1 & $\operatorname{PCC}(\mathrm{R})$ & $\mathrm{N}$ & 3.4 & 1.03 & 1.1 & $\operatorname{PCC}(R)$ & $\begin{array}{c}\text { Right } \\
\text { adrenalectomy }\end{array}$ & 21 & Cured & $\operatorname{PCC}(\mathrm{R})$ & TN \\
\hline
\end{tabular}

Mass diameter: represented the longest diameter of left/right adrenal lesions.

ARR: Aldosterone-to-renin ratio, the ratio of plasma aldosterone concentration and plasma renin activity (a plasma renin activity $<0.1 \mathrm{ng} / \mathrm{ml} / \mathrm{h}$ was considered 0.1 $\mathrm{ng} / \mathrm{ml} / \mathrm{h})$.

24h-NE: 24h-Noradrenaline

24h-UFC: 24h-Urinary free cortisol

APA: Aldosterone-producing adenoma

IAH: Idiopathic aldosterone hyperplasia

sUAH: suspected unilateral adrenal hyperplasia

NFA: Nonfunctioning adrenal adenoma

CPA: Cortisol-producing adenoma

PCC: Pheochromocytoma

AVS: Adrenal venous sampling. Lateralization was defined as an aldosterone/cortisol ratio (lateralization index) of $>6: 1$

Captopril challenge test: The positive Captopril challenge test was defined as a decrease in plasma aldosterone level after captopril administration by $\leq 30 \%$.

R: right; L: left; B: bilateral 


\section{The ${ }^{68}$ Ga-pentixafor uptake and outcomes}

To evaluate the value of using pentixafor uptake for patient management and prognostic estimations, postoperative patients were categorized into the following cohort 1) patients who underwent adrenalectomy on pentixafor-avid lesions. Cohort 2) patients who underwent adrenalectomy on nonpentixafor-avid lesions.

To determine the significance of ${ }^{68} \mathrm{Ga}$-pentixafor in the prediction of clinical outcomes, the 48 patients who underwent surgery were stratified based on their therapeutic strategies in correlation with PET/CT findings. In the first cohort of 42 patients $(87.5 \%)$ who underwent adrenalectomy for ${ }^{68}$ Gapentixafor-avid nodules, 30 patients were cured, and 12 patients were improved. In the second cohort of six patients (12.5\%) who underwent adrenalectomy on non-pentixafor-avid lesions ( 2 patients were improved, while 4 patients were non-improved). The 100\% (42/42) patients in the first cohort versus 33.3\% (2/6) patients in the second cohort have achieved the preferable outcome (Supplemental figure 1).

In fact, in our study, Seven APA patients were primarily misdiagnosed as IAH or NFA or with the wrong lateralization by CT scans and subsequently received adrenal adrenalectomy guided by ${ }^{68} \mathrm{Ga}$-pentixafor PET/CT, and all these patients achieved the preferable outcome. In addition, one IHA patient avoided surgery guided by negative PET/CT findings. 


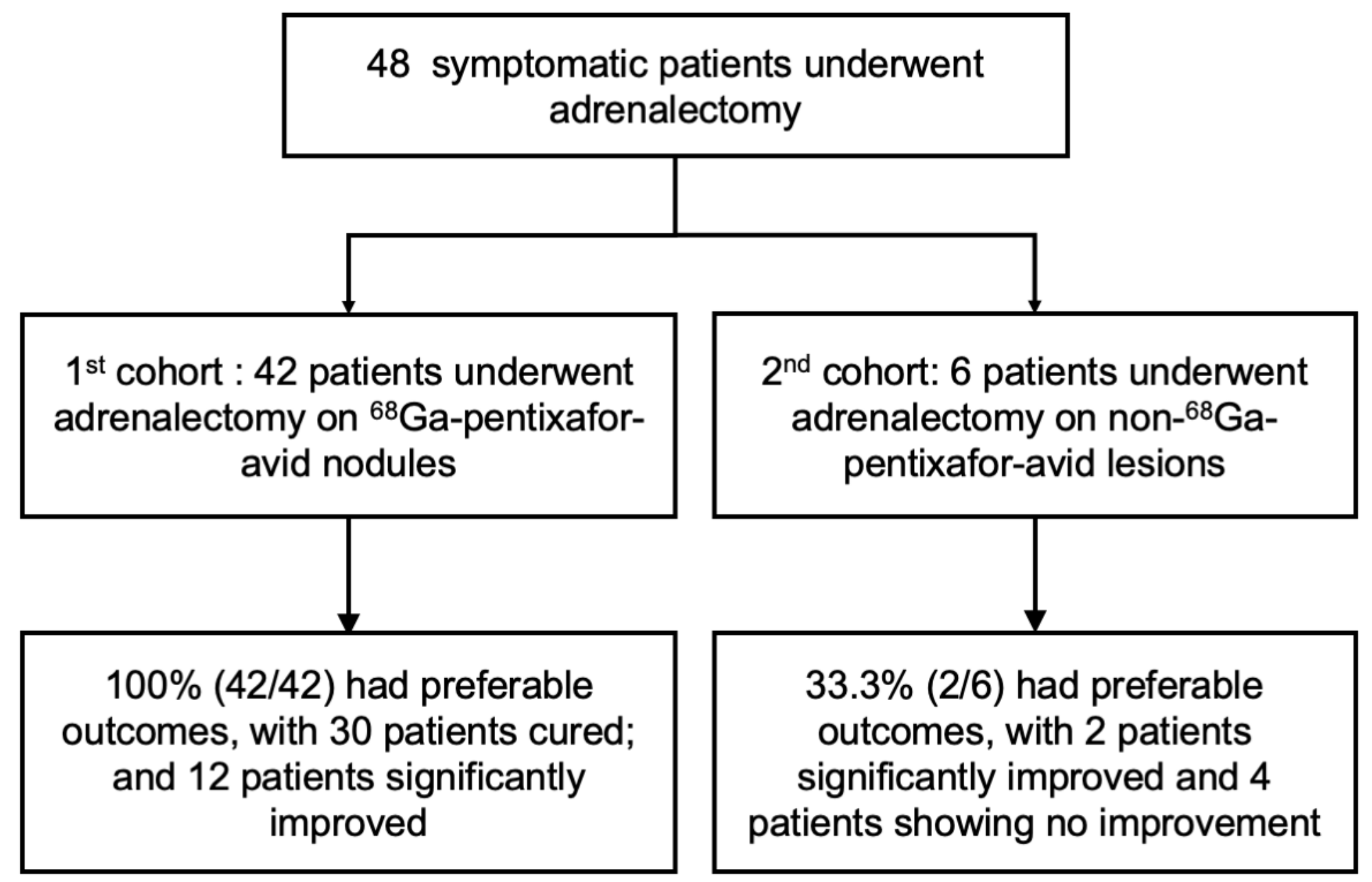

Supplemental figure 1. Flow diagram of the therapeutic management of symptomatic patients who underwent adrenalectomy in order to evaluate the prognostic value of ${ }^{68} \mathrm{Ga}$-pentixafor $\mathrm{PET} / \mathrm{CT}$ imaging. 


\section{Reference}

(1) Williams TA, Lenders JWM, Mulatero P, et al. Outcomes after adrenalectomy for unilateral primary aldosteronism: an international consensus on outcome measures and analysis of remission rates in an international cohort. Lancet Diabetes Endocrinol. 2017;5:689-699.

(2) Lacobone M, Citton M, Viel G, et al. Unilateral adrenal hyperplasia: a novel cause of surgically correctable primary hyperaldosteronism. Surgery. 2012;152:1248-1255.

(3) Webb SM, Badia X, Barahona MJ, et al. Evaluation of health-related quality of life in patients with Cushing's syndrome with a new questionnaire. Eur J Endocrinol. 2008;158:623-630. 